UC-34

Reporting Date: February 1975 Issued: March 1975

\title{
An Introduction to Explosive Magnetic Flux Compression Generators
}

\author{
by
}

C. M. Fowler

R. S. Caird

W. B. Garn

An Alfirmalive Action/Equol Opportunity Employer 
Work partially supported by Air Force Weapons Laboratory, Defense Advanced Research Projects Agency, U.S. Air Force Foreign Technology Division, and U.S. Army Materiel Command, MICOM.

Printed in the United State of America. Available trom Notional Technical Information Service U.S. Dopostmant of Commerce 5285 Port Royal Rood Springtiold. VA 22151

Prico: Prioled Copy if DO Microtiche \$2.25

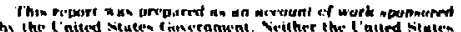

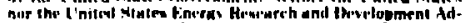
minsuseslion, mur ant of their empliseren, nat ans of their eson-

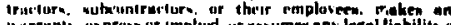

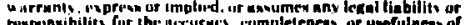

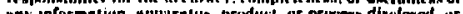

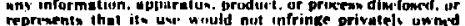
rixhls. 


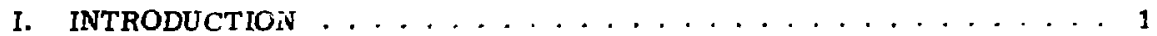

II. EXPLOSTVES MAGNETIC FLUX-COMPRESSION

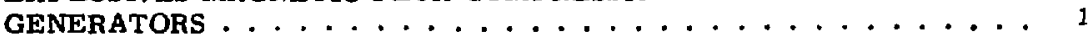

A. Elementary Generator Theory ... . . . . . . . . . . . . 2

B. Types of Gerierators. . . . . . . . . . . . . . . . . . . 4

1. Spiral or Helical Generators. . . . . . . . . . . . . . . . 4

2. Plate Generators . . . . . . . . . . . . . . . 6

3. Strip Generators . . . . . . . . . . . . . . . 7

4. Cylindrical Implosion Systems . . . . . . . . . . . . 8

5. Coaxial or Cylindrical Generators. . . . . . . . . . . . 10

6. Spherical Generators ..................... 11

C. Initial Energy Sources. . . . . . . . . . . . . . . . 11

1. Primary Energy Sources ................... 11

a. Direct Feed ..................... 11

b. Indirect or Inductive Feed ................ 12

(1) Elimination of Perturbations ............ 12

(2) Reduction in Size of Initial Energy Supply ........ 13

(3) Overcoming Source Inductances . . . . . . . . . 14

(4) Reduction of Magnetic Forces . . . . . . . . . . 15

2. Generators as Intermediate Energy Boosters . . . . . . . . . 16

a. Energy Boosting . . . . . . . . . . . . . . 17

b. Force Reduction .................... 17

D. Technical Aspects of Generator Technology . . . . . . . . . . . . 18

1. Switching and Pulse Shaping ................. 18

2. Use of Transformers . . . . . . . . . . . . . . . 20

3. Generator Limitations ... . . . . . . . . . . . . . 22

a. Flux Losses ... . . . . . . . . . . . . . . 24

b. High Magnetic Field Effects. . . . . . . . . . . . 25

c. Internal Voltage Limitations ............... 27

E. Energizing through Transformers . . . . . . . . . . . . . 29

NOTICE

This report was prepared as an account of work sponsored by the United States Government. Neither the United States nor the United States Eneryy Research and Development Administration, nor any of thed employees, nor any of their contractors, subcontractors, or their employees, makes any wrranty, express or implied, or assumes any liability or responsibility for the accuracy, completeness or usefulness of any it:formation, apparatus, protuc' process disclosed, or represents that its use would i infringe privately owned rights. 


\title{
AN INTRODLCTION TO EXPLOSIVE MAGNETIC FLUX COMPRESSION GENEFATORS
}

by

\author{
C. M. Fowler, R. S. Caird and W. B. Garn
}

\begin{abstract}
Various types of explosive flux compression generators are illustrated and their relative advantages are compared. Experiments are described in which energy was supplied by these generators. The experiments were selected to show both versatility and limitations of the devices. Generator principles are derived from lumped parameter circuit theory.
\end{abstract}

\section{INTRODUCTION}

Explosives flux compression devices have been discussed frequently in the literature in recent years. However, for the most part, available treatments of the subject have been specialized.

This report gives a rather thorough background covering most aspects of explosives flux compression technology, but not at a very detailed level. Instead, the text has been developed more towards unifying the subject. Various applications are mentioned, but the emphasis has been on those in which the Los Alamos Scientific Laboratory has been involved. Some coherence has been given to the report by considering in later sections a specific example, that of using such a device to supply a large amount of energy to a sizeable inductance load. It is shown that many aspects of the technology must be con sidered before a tentative solution to the problem is obtained. The discussion is largely descriptive, and throughout, circuit theory analys is has been employed. When more detalled analys is is required, such as a discussion of magnetic lield diffusion, other references may be consulted. 1,2
11. EXPLOSTVES MAGNETIC FLUX-COMPRESSION GENERATORS

The general principles of explosives magnetic flux-compression devices have been reasonably well documented. ${ }^{3-7}$ In general, chemical explosives are used to compress an initial magnetic flux by driving part, or all, of a conducting surface which contains the flux. Work done by the conductors moving against the magnetic fields results in an increase in the electromagnetic energy. The additional enerfy comes originally from the chemical energy stored in the explosives, a part of which is transmitted to the moving conductors. These devices are normally called flux-compression generators or, more simply, generators. The explosively driven conductors are frequently called armatures, and occasionally, nondriven elements of the generators are called stators.

Elementary generator theory is presented

in Sec. II. A, different classes of generators are described in Sec. II. B, and the means of supplying initial generator energy are discussed in Sec. II. C. More technical aspects of generator technology are treated in Sec. II. D, which also includes a discus sion of operating limitations. A specific example, 
that of delivering $10^{9} \mathrm{~J}$ to an inductive loaci of $10 \mu \mathrm{H}$, shows how limitations affect the design of a generalor system. Attempto to energize the load by direct generator feed would be thwarted by the development of excessive internal generator voltages. Calculations baged upon idealized sygtems are given in Sec. II. E and indicate that the diffirulties can be resolved by transfornser-coupling the luad to a generator-driven primary coil.

\section{A. Elementary Generator Theory}

Figure 1 shows the basic components of a cluss of generators of the helical or spiral type. At the lower right is a fixed external load coil, of inductance $L_{l}$. which is to be energized by the gonerator. The generator itself consists of the external helical winding. together with the explosive-loaded metal cylinder, or armature. Initial flux is supplied to the generator and series load

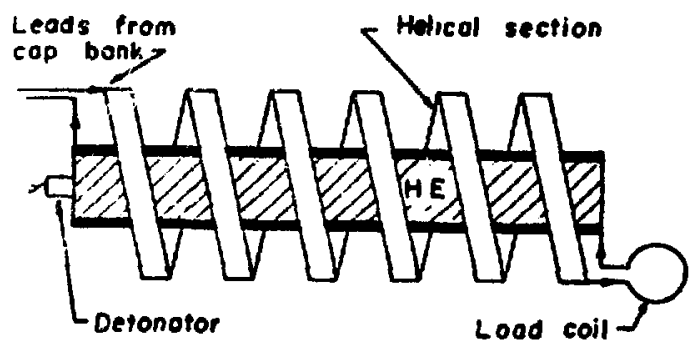

1*1g 1. Sprral generator. before explosive int tat ion

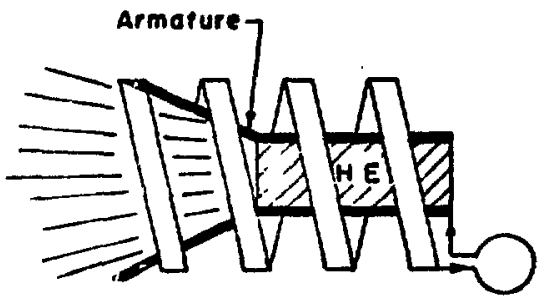

Fig. 2. The generator of Fig. 1 at a late stage after explosive detonation. coil from a capacitor bank. It can be seen that the armature itself serves as part of the conducting circuit. When the explosive is detonated, the armature expands, resulting in a conical metal front moving with explosive detonation velocity. The detcration is so timed hat this conical front shorts out the generator iuput at or near peak current or, equivalently, peak flux in the generator. This also effectively isolates the capacitor bank from the system. After closure of the current input, the conical front proceeds down the armature, contacting the helical turns in a more or less wiping fashion. Figure 2 gives a view of the generator fairly late in the detonation stage. The inductance of the generator is roughly proportional to the square of the number of turns in the helix, and inversely proportional to the remaining length over which the turns are spaced. The generator inductance $\mathrm{L}_{\mathrm{G}}$ thus varies more or less continuously with time from its initial value $L_{0}$ to zero after armature motion has ceased.

If the current densities developed in the generator do not get large enough to distort the system, the generator inductance can be given as a function of the time. Under this condition, the generator circuit can be drawn schematically as shown in Fig. 3. Here the generator is shown as a variable inductance $L_{G}(t)$, and the external load to be energized is $L_{1}$. Allowance for source or waste inductance (from various external leads to the load, residual generator inductance, etc.) is indicated by $\ell_{0}$, and circuit resistance is shown as $R$. The equation governing the performance of this circuit is then:

$\frac{d}{d t} L\left(L_{G}+\ell_{0}+L_{1}\right) I J+I R=0 I(0)=I_{0}$

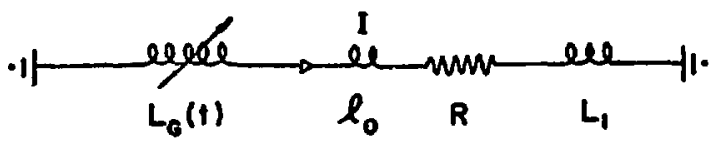

Fig. 3. Schematic of generator circuit. The load coil $L_{1}$ is in series with the generator. 
Time is measured from the instant that the armature shuts off the current input, at which time the current is $I_{o}$ and the initial generator inductance is $L_{G}(0)$, denoted by $L_{0}$ below.

If the circuit were perfectly conducting, $\mathrm{R}=$

0 , the well-known electrodynamic result is recovered that flux $\mathrm{LI}$ is conserved in a perfectly conducting circuit. Under this condition, the conservation of flux leads to the result:

$$
I=\frac{L_{0}+\ell_{0}+L_{1}}{L_{G}+\ell_{0}+L_{1}} I_{0}
$$

The inductive energy in the circuit, $\mathbf{E}=$ $1 / 2\left(\mathrm{~L}_{\mathrm{G}}+\ell_{\mathrm{o}}+\mathrm{L}_{1}\right) \mathrm{I}^{2}$, can be related to the initial circuit inductive energy, $E_{0}=1 / 2\left(L_{0}+l_{0}+L_{1}\right)$ $x \mathrm{I}_{0}^{2}$, as follows:

$E=\left(\frac{L_{0}+\ell_{0}+L_{1}}{L_{G}+\ell_{0}+L_{1}}\right) E_{0}$.

Under burnout conditions, $L_{G}=0$, the final current and circuit energy become:

$$
\begin{aligned}
& I=\frac{L_{0}+L_{0}+L_{1}}{L_{0}+L_{1}} I_{0} \\
& E=\frac{L_{0}+\ell_{0}+L_{1}}{L_{0}+L_{1}} E_{0} .
\end{aligned}
$$

The resistance $R$ in an actual circuit is usually related to the generator action in a complex way. Among the significant factors affecting the resistance are changes in conductor skin depth, temperature, and path length as generator action proceeds. For illustrative purposes, however, we consider the case where $R$ is constant. If, further, the inductances in the generator circuit are functions only of the time, the solution of $\mathrm{Eq}$. (1) is

$I(t)=1 \frac{L_{0} T^{(0)}}{L_{T}(t)} \exp \left[-\int_{0}^{t} \frac{R}{L_{T}^{(y)}} d y\right]$ where we have abbreviated the total circuit inductance $L_{G}+\ell_{0}+L_{1}$ by $L_{T}$.

The inductive energy $E$ becomes

$$
E(t)=E_{o} \frac{L_{T}(o)}{L_{T}(t)} \exp \left[-2 \int_{0}^{t} \frac{R}{L_{T}(y)} d y\right]
$$

We consider the case where both the load inductance $L_{1}$ and the loss inductance $\ell_{0}$ are constants and we employ the following specialized form for the generator inductance:

$L_{G}(t)=L_{0}(1-t / \tau) 0 \leq t \leq \tau$.

This inductance form approximates that for the plate generator discussed in Sec. II. B with initial inductance $L_{0}$ and burnout time $\tau$. Equations (6) and (7) then reduce to the following:

$I(1)=I_{0}\left[\frac{\mathrm{L}_{\mathrm{T}}(\mathrm{u})}{\mathrm{L}_{\mathrm{T}}(\mathrm{t})}\right]^{1-\frac{\mathrm{RT}}{\mathrm{L}_{0}}}$

$E(t)=E_{0}\left[\frac{L_{T}(o)}{L_{T}(t)}\right]^{1-\frac{2 R T}{L_{o}}}$.

At burnout, $t=\tau$, the current and energy are at a maximum. The energy is distributed between the two inductances $\ell_{0}$ and $L_{1}$ in proportion to their inductances. The maximum current and energy inio the load $L_{1}$ therefore becume

$I(\tau)=I_{0}\left(\frac{L_{0}+L_{0}+L_{1}}{f_{0}+L_{1}}\right)^{1-\frac{R \tau}{L_{0}}}$

$E_{1}(\tau)=E_{0} \tau_{1}^{L_{1}}\left(\frac{L_{0}+L_{0}+L_{1}}{l_{0}+L_{1}}\right)^{1-\frac{2 R T}{L_{0}}}$ 
It is clear from these equations that the quant ity Rr/Lo must be less than 1 for current amplification, and less than 0.5 for energy multiplication. As a specific example, consider a generator having the form indicated by Eq. (8), with an initial inductance of $l \mu H$ and a burnout time of $10 \mu \mathrm{s}$ powering a load of $10 \mathrm{nH}$. Assume a source or loss inductance of $2 \mathrm{nH}$, a resistance of $10 \mathrm{~m} \Omega$ and an initial current of $5 \times 10^{5} \mathrm{~A}$. 'The initial energy in the circuit becomes:

$E_{0}=1 / 2 I_{0}^{2}\left(L_{0}+\ell_{0}+L_{1}\right)$

$=1 / 2\left(5 \times 10^{5}\right)^{2} \times\left[1.012 \times 10^{-6}\right]=126.5 \mathrm{~kJ}$.

From Eqs. (11) and (12) the current and energy multiplications at burnout become:

$I(\tau) / I_{\mathrm{o}}=\left(\frac{1.012}{0.012}\right)^{0.9}=(84.5)^{0.9}=54 ; I=27 \mathrm{MA}$,

$\mathrm{V}_{1}(\tau) / \mathrm{E}_{0}=\frac{0.010}{0.012}\left(\frac{1.012}{0.012}\right)^{0.8}=\frac{10}{12} 35=29.2 ;$

$\dot{E}_{1}-3.7 \mathrm{MJ}$

It is rlear that good gencrator practive talls for a minimum of carcuit resistance and source tudurtance. If the resistance were negligible, the "urrent multiplication would be 84.5 and the energy mulitplication 70.5. If the source inductance viere aiso negligible, both current and energy multipli'at tons would be 101 .

While the condition for current muttiplicat ton. $R+/ L_{0}<1$, was derived for a specific generator form, a related type of restriction applies more fenerally. This may be seen by expanding Fi. (1) :

$I \frac{d L}{d t}+L_{G} \frac{d I}{d t}+\ell_{0} \frac{d I}{d t}+I R+L_{1} \frac{d I}{d t}=0$.
The last four terms, in comparison with the circuit sketch of Fig. 3, can be seen to represent voltage drops across the load inductance, the resistance, the source inductance, and the residual inductance in the generator. The first term is the potential across the moving armature and, in fact, is the source voltage for the rest of the sireuit. The term $\left|\mathrm{dL}_{\mathrm{G}} / \mathrm{dt}\right|$ is somewhat analogous to a resistance and is sometimes referred to as such. For the simple generator form used abuve, the ratio $\mathrm{HT}_{\mathrm{T}} ! \mathrm{L}_{\mathrm{o}}$ is, in fact, $\mathrm{R} /\left|\mathrm{dL} \mathrm{L}_{\mathrm{G}} / \mathrm{dt}\right|$. In general, for current multiplication the circuit resistance must be less than some weighted value of $\mid \mathrm{dL}_{\mathbf{G}}$ idl | for a generator with arbitrary time dependence.

It is also clear from Eq. (13) that the generator arinat ure potential $\mathrm{I}\left(\mathrm{dL} \mathrm{L}_{\mathrm{G}} / \mathrm{dt}\right.$ ) must exceed the voltage drop across the resistance $I R$, or the initial current must decrease with time.

For the generator example given earlier, the armature or drive voltage becomes at burnout:

$$
V_{A}=I \frac{d L_{G}}{d t}=-\frac{I L_{0}}{T}=-27 \times 10^{6} \frac{10^{-6}}{10^{-5}}
$$

$=-2.7 \mathrm{MV}$.

"This is a very large internal voltage for a generator to sustain, and most generators cannot do so. Manageability of internal voitages is a generator constraint which will be diseussed later.

B. Iypes of Generators

Almost any number of gererator types can b. conceived but very few turn out to be practicable. The most useful generator types will be described below, together with some of their variants.

1. Spiral or Helical Generators. A schernatic drawing of a generator of this class is shown in Fig. 1 , an- its operation is described in Sec. II. A. These generators are characterized by 
very large initial inductances owing to the multiple turn windings of the spiral. The inductance $L$ of a helix of $n$ turns and radius $R$ over a length $\omega$ is given approximately by:

$L=3.95 \frac{n^{2} R^{2}}{\omega+0.9 R} u H(M K S)$

$L=0.1 \frac{n^{2} R^{2}}{\omega+0.9 R} \quad \mu H(R, w$, inches $)$.

These two formulas will be used frequently in this report and a discussion of their limits will be helpful. General applicability of the formula is given by Terman. ${ }^{8}$ The square of the radius in the numerator arises from the area inside the circular windings over which flux is measured. For spiral generators, this term is replaced by the difference between the squares of the radii of the helix and the armature, since flux is largely excluded from the area occupied by the armature. In cases where the flux-containing area is not circular, an adequate approximation can frequently be obtained by using this area divided by $\pi$ in place of $R^{2}$. The radial term in the denominator is an edge effect correction term which makes allowance for the finite length of the solenoid. For spiril generators the edgc effect correction term should account only for the finite thickness of the annular space between helix and armature instead of the entire area enclosed by the helix. Half of the annular radial separation serves better for the edge correction here. Strictly speaking, the formula is applicable only when the current density is uniform. This does not lead to appreciable error for multiple-turn coils. For wide conductors, as in single-turn coils where the width is comparable to the coil diameter, the currents are more concentrated near the ends of the conductors. For these cases, inductances calculated from the formulas may be too large by 10-20\%.

As a specific example, a generator with initial armature radius of $0.1 \mathrm{~m}$, and spiral section of 20 turns, radius $0.2 \mathrm{~m}$, and length $0.5 \mathrm{~m}$ has an inductance of $87 \mu \mathrm{H}$, according to Eq. (15a). This large inductance is to be contrasted with the calculated inductance of $0.22 \mu \mathrm{H}$ for a single-turn solenoidal generator of the same dimensions. The $0.22-\mu \mathrm{H}$ value is more typical of those for the other generator classes considered later.

In principle, Eqs. (4) and (5) indicate that enormous current and energy multiplications are possible in low inductance loads. In practice, a number of factors severely limit spiral generator performance. Internal generator voltages are more limited because of the possibility of breakdown between turns of the helix. Generally speaking, such generators operate over fairly long times, and under these conditions maximum cur rent densities are limited to values of order $1 \mathrm{MA}$ per centimeter of conducting path. Thus, if the generator is to deliver a current of $20 \mathrm{MA}$, the turns near the generator output should be of order $20 \mathrm{~cm}$ wide. Other limitations arise from the tendency of these generators to pocket flux if the turns are spaced too closely. Pocketing occurs when the expanding cone of the armature shorts out part of a turn before completely wiping out a preceding turn. Good spiral generator design therefore calls for relatively widely spaced turns, wide output turns, and close machining tolerances on both the armature and the helical section.

The relatively long generation time for this class of generators limits their use in many applications. Nevertheless, they have been used successfully as power sources for $\theta$-pinches 9,10 and plasma guns, ${ }^{11}$ although both applications required that the plasma devices be switched into the circuit at a relatively late time in the generation period. The time scale of operation of these generators also suggests their use as power sources for certain laser devices and for charging water capacitors when portability is a factor. 
Most of our own generator applications for the near fut ure call for much faster generators. The spiral generator is expected to be invaluable as an intermediate energy booster--that is, it will amplify the energy from the initial source to supply the starting energy for the final, or output, generator.

2. Plate Generators. The cross-sectional view of a plate generator is shown schematically iv Fig. 4. Shown at the right is a solenoidal load coil connected to the generator by a transmission line. Explosive blocks are placed upon the upper and lower plates of the generator, as shown. Initial flux is supplied to the generator by a capacitor bank through the small, open slot shown at the upper left side of the generator. Current flow through the generator conductors is indicated by arrows, and the fieid developed in the generator cavity by the current is indicated by crosses.

The explosive blocks are detonated simultaneously over their outer surfaces at such a time that the input current slot is closed at, or near, peak input current. This operation simultaneously eliminates the capacitor bank from further interaction with the system and traps the initial flux in a completely enclosed metal system. The josition of the driver plates at a later time is shown by dashed lines, each plate moving with velocity $v$.

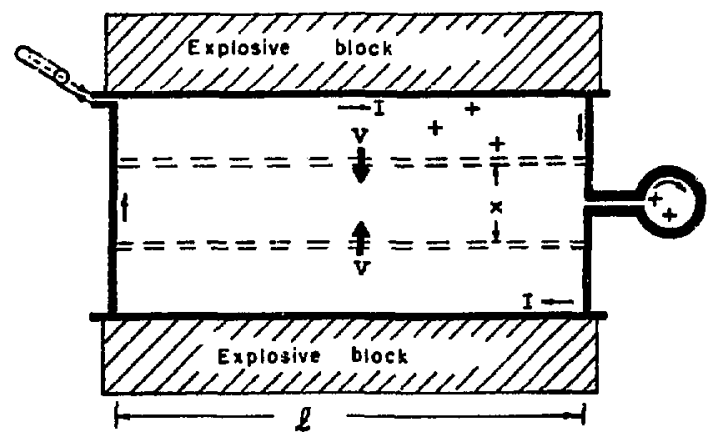

Fig. 4. Plate generator schematic. A later generation stage, after explosive initiation, is shown by the new position of the horizontal plates indicated by dashed lines.
The flux-compression process of the generator is then evident.

The width of the generator, perpendicular to the plane of the figure, is denoted by $\omega$ and the length, as shown on Fig. 4, by $\ell$. When the top and bottom plates are separated by a distance $x$ the generator inductance is given by Eq. (16).

$L=\frac{\mu \ell X}{\omega}=1.257 \frac{\ell X}{\omega} \mu H(M K S)$.

If the cross-sectional ares $\perp^{x}$ is wxitten as $I$ times an effective radius squared, the inductance formula becomes identical to that of Eq. (15a) for a one turn solenoid with no edge correction.

The explosively driven plates generally accelerate somewhat in their early stages of motion, but gradually approach a maximum velocity which is governed by the plate and explosive types and thicknesses. After this stage is reached, $i$ is then given by

$\dot{L}=-\mu \frac{\ell}{\omega} \cdot 2 v$.

This approximate constancy of $\dot{L}$ forms the basis of the statement that the generator inductance formula of Eq. (8) approximates that for a plate generator.

The ratio of the generator length to its width $\ell / \omega$ enters Eqs. (16) and (17) and is usually referred to as the number of squares in the generator. Thus the inductance of such a generator is $1.257 \mu \mathrm{H}$ per meter of plate separation for cach square, or 1.257 turi for each millimeter of plate separation per square. Initial plate separations for such generators seldom exceed $0.1 \mathrm{~m}$, and initia! inductances are iherefore in the few-tenths microhenry range, depending upon the number of squares. For reasonable current and energy arnplification, load inductances must therefore be limited to a maximum of a few tens of nanohenrys. In this connection it might be remarked that the inductance of the transmission line (Fig. 4) which connects the generator to the load, and is a source 
or loss term, is also given by Eq. (16). Even for transmission line plate separations of only a millimeter, the loss inductance exceeds $1 \mathrm{nH}$ per square. Such transmission lines should be kept as short and wide as possible and separated by the smallest distance compatible with voltage standoff.

The major advantages of plate generators include relative simplicity of const ruction, enormous curment-carrying capacity which is controlled by their widths, and the short time scale over which they may be operated. Development of new detonation systems now allows initiation of large areas of explosives with high simultaneity. This advance has probably opened up new areas for generator applications.

3. Strip Generators. The cross section of a strip generator is shown schematically in Fig.

5. Initial flux is introduced into the system which consists of the generator and the load coil. The direction of current flow is shown by arrows and the magnetic fields by crosses. Detonation of the explosive is timed to short the current inpu slot at peak current, or flux, in the system. As detonation proceseds down the explosjve strip, the top plate of the generator is driven downward, as pictured by dolted lines for one time stage of the detonation. The flux-compression process is evident.

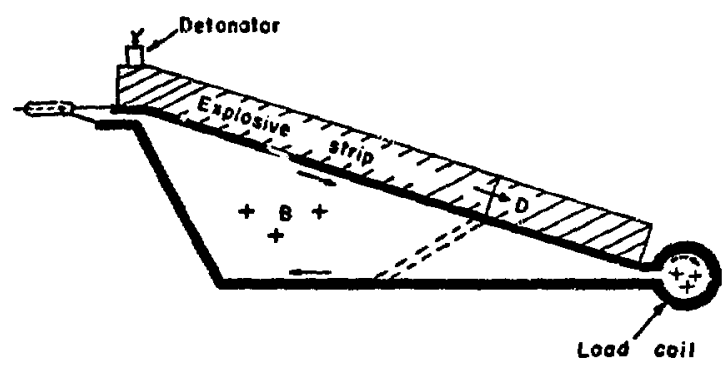

Fig. 5. Strip generator schematic. Detonation proceeds dowri the explosive strip and a later gcneration stage is indicated by the new position of the top conductor shown by dashed lines.
The inductance of the generator at any stage of detonation is again given approximately by Eq. (15a), where the $\operatorname{term} w$ is the width of the generator perpendicular to the figure and the effective radius is that of a circle whose area equals the remaining generator cross section. Initial inductances of such generatcrs seldom exceed a few tentiss of a mic rohenry. Generators of this type are the least expensive to construct. They can also be constructed to have large current carying capacity by making the widths suitibly large. Consequently, they have been used extensively for generating high magnetic fields in large volumes (typically in the low megagauss range). They can also be used with advantage to make initial studies for programs that require new generator tes hniques.

The most common variant of this rlass of generators has explosive strips on both upper and lower plates. In this case, the metal contour is altered in such a fashion that the driver plates form, in cross section, the equal arms of an isosreles triangle. In another variant of this generator ype, Bichenkov ${ }^{12}$ claims that $19 \%$ of the initial explosive energy was converted to magnetic energy. This is the largest such conversion efficiency reported to date.

4. Cylindrical Implosion Systems. Several views of a cylindrical implosion system are shown schematically in Fig. 6. Two of the sketches show the system before detonation. The Init tal assembly consists of a thin-walled cylinde centered within an explosive ring charge to which is attached a ring of high quality detonators. The thin-walled metal cylinder, usually called a liner, plays the role of the generator armature. An initial flux is induced within the liner, in most cases by passing current through a coil pair external to the system. (See also Ssc. II. C. I.b.) Detonation of the charge is timed to correspond to peak flux in the liner. The third sketch shows the position of the liner at a later stage in the implosion. 


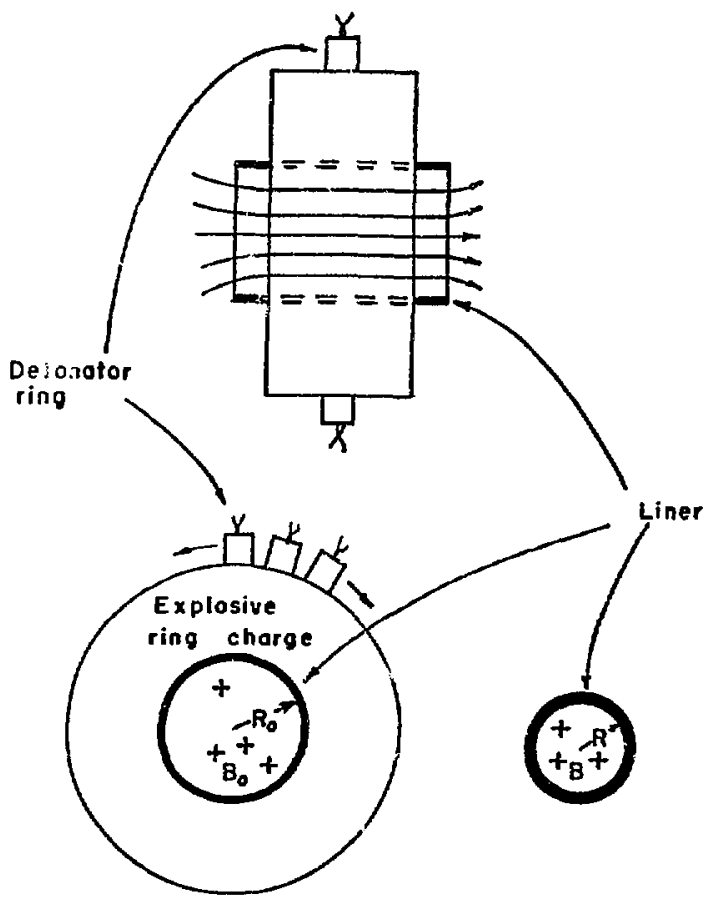

Fig. 6. Views of a cylindrical implosion system. The upper and lower left figures show the system before implosion. Cylindrical. implosion is achieved by simultaneously initiating the row of high quality detontors mounted on the ring charge. The lower right figure shows a view of the liner at a later stage of the implosion.

Insofar as the liner may be assumed to be a perfect conductor, flux within it is conserved according to basic electromagnetic theory. The following relation then obtains:

$B_{O} R_{0}^{2}=B R^{2}$

We cant obtain the same relation from engineering circuit theory as follows: In the absence of end corrections, the inductance of the cylinder is given approximately by Eq. (15) for a single-turn solenoid where the term $\omega$ is the length of the liner. Conservation of flux. LI then shows that the liner currents vary inversely as $R^{2}$. Since the magnetic field is also proportional to the current, Eq. (18) is then recovered. Typisal initial liner inductances are usually snly a few tens of nanohenrys since most liner radii and lengths are only a few centimeters.

This class of generators is of historical interest because it was the first type discussed in the open literature. ${ }^{3}$ Magnetic fields in excess of 15 MG, the largest ever achieved terrestrially, have been produced in some systems. Such fields contain the most concentrated electromagnetic energy density ever produced over an experimental region--almost a megajoule per cubic centimeter or over $5 \mathrm{ev} / \AA^{3}$.

Owing to the rapid rate at which area is decreased during the latter stages of implosion, field rises commonly achieve values in excess of $15 \mathrm{MG} / \mu \mathrm{s}$. The rate of field increase is one measure of the speed of generator operation. In this sense, cylindrical implosion systems are faster than other generators by an order of magnitude or more. Rates of current increase are also used at times to classify generator speeds. However, this rate is not intrinsic to a generator class since current-carrying capacity can usually be altored by varying the width of the generator conductors without appreciably changing the generation time scale.

Cylindrical implosion systems are expensive. Great care must be exercised to maintain as symmetric an implosion as possible. Liner dimensionis must be held to very close tolerances and only the highest quality explosive systems can be tolerated. Only rarely is the region of highest fields (a small region near the center of the liner) suitable for experimental use. However, there have been recent impressive advances in the use of transformers in high field environments. Thus, these systems in combination with a centrally located transformer cannot be ruled out as power sources for some high speed applications.

\section{Coaxial or Cylindrical Generators.}

The upper sketch of Fig. 7 shows a coaxial 

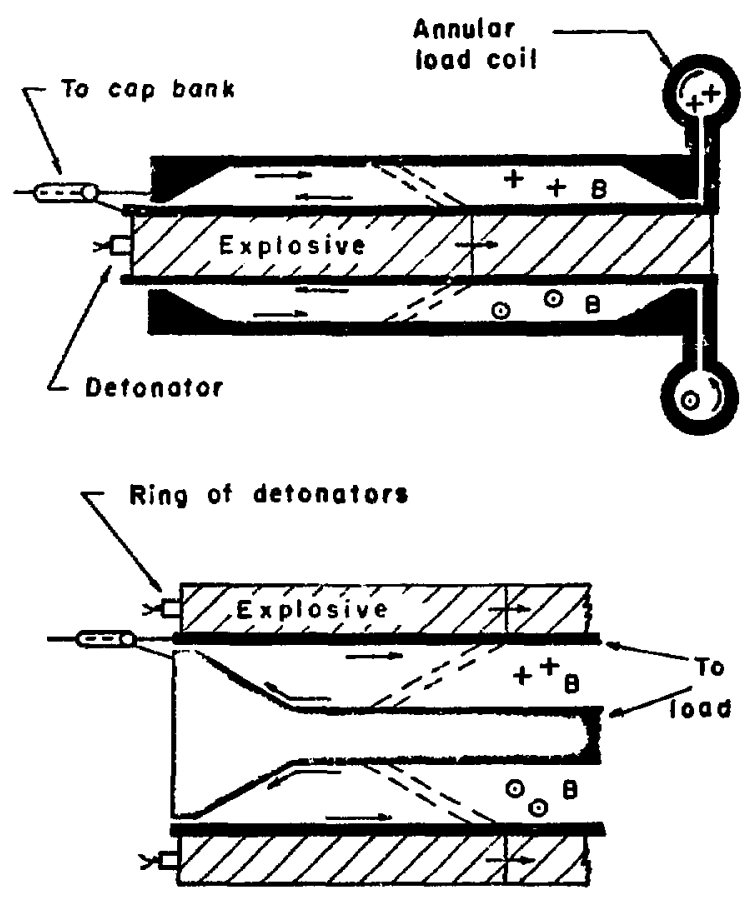

Fig. 7. Coaxial or cylindrical generators. The upper figure shows basir. components, consisting of an inner, explosive loaded armature and a cylindrical outer stator. A later generation stage, after explosive initiation, is indicated by the conical armature front moving with detonation velocity and shown by dashed lines. A variant of this construction with external armature and internal stator is shown in the lower figure.

generator and load coil. Generators of this type are upor occasion also called cylindrical generators. The basic generator components include the stator, or cuter cylinder, and the armature, the explosiveloaded imner cylinder. The load coil pictured is annular or doughnut-shaped. Initial current is supplied by a capacitor bank through the annular input slot at the left. Arrows show that the currer:i flows along the outside cylinder, through the load coil, and back through the armature. Magnetic field lines $B$, indicated by circles and crosses, are circular or tangential. They encircle the armature and are restricted essentially to the annular space between the statox and armature and to the load coil.
Detonation of the armature explosive is again timed to close the input current slot at such time that maximum current or flux is in the system. As detonation proceeds, the armature expands in a conical front which moves with detonation velocity. Again, the manner in which flux is compressed is clear.

The lower sketch of Fig. 7 shows the most common variant of this class of generators. Here the central cylinder plays the role of stator, while the outer cylinder becomes the armature. 'The explosive, in the fcrm of a hollow cylinder, is detonated by a ring of detonators, shown at the left of the figure. The conical front of the armature at one instant of detonation is shown by dotted lines.

The inductance of a coaxial generator of length $\ell$ and $w$ ith outer and inner radii (stator and armature for the upper sketch of Fig, 7) $R_{2}$ and $R_{1}$ is given by Eqs. (19):

$L=\frac{\mu \ell}{2 \pi} \log R_{2} / R_{1}$

$L=0.2 \log R_{2} / R_{1} \mu H / m$.

The above inductance formulas apply only to a system where the two cylinders are of equal length and the end conductors are perpendicular to the cylinders. Corrections must be made for various conical end conductors arising from the armature expansion, as weil as those built into the system initially (Fig. 7). Initial inductances of coaxial generators are also small, seldom exceeding a few tenths of a microhenry. As an example, from Eq. (19b) a cylindrical generator of $1.5-\mathrm{m}$ length, with stator radius of $30 \mathrm{~cm}$ and armature radius of 10 $\mathrm{cm}$, has an initial inductance $\mathrm{L}_{\mathrm{G}}(0)=(1.5)(0.2)$ $x \log (30 / 1.0)=0.33 \mu \mathrm{H}$.

This class of generators is characterized by high current-carrying capability and ruggediess. Since current flows along the cylindrical axes, the 
minimum width available for carrying current is the circumference of the inner cylinder. In the above example the armature, with a radius of $10 \mathrm{~cm}$, has a width of about $63 \mathrm{~cm}$ available for the current. Such a generator could carry gbout 100 MA for a microsecond or two.

The rugged nature of the generator can be seen from Fig. 7. As mentioned earlier, explosive energy is converted to magnetic energy by forcibly moving the generator armature against magnetic fields trapped in the generator and load circuit. The generator effectiveness therefore improves as the magnetic fields increase. The magnetic fields, in turn, exert pressure on the conducting elements of the generatur. In the case of the cylindrical generator, the pressures tend to compress the inner cylinder and expand the outer one. Because both conductors form complete closed surfaces, they can sustain much greater magnetic pressures. The spherical generator discussed below, as well as the cylindrical implosion system a $1 d$, with some reservations, the plate generator discussed earlier, are also rugged. This is in contrast to spiral and strip generators which are of flimsier construction and are often limited in performance by magnetic forces.

6. Spherical Generators. The sketch of a spherical generator is shown in Fig. 8, together with an annular or doughnut-shaped load coil. The generator consists of sectors of two spheres joined together with conical conducting glide planes. Initial flux is developed in the system through the input current leads connected acress the circular opening between the inner spherical sector and the left conibal section. The inner spherical sector is driven by the explosive device (shown cross-hatched) and plays the role of the armature. The outer spherical sictor is the stator. The explosive device is detonated at such a time that the expanding armature shorts out the current input opening at peak input current. Directions of current flow are indicated by arrows adjacent to the conductors. The

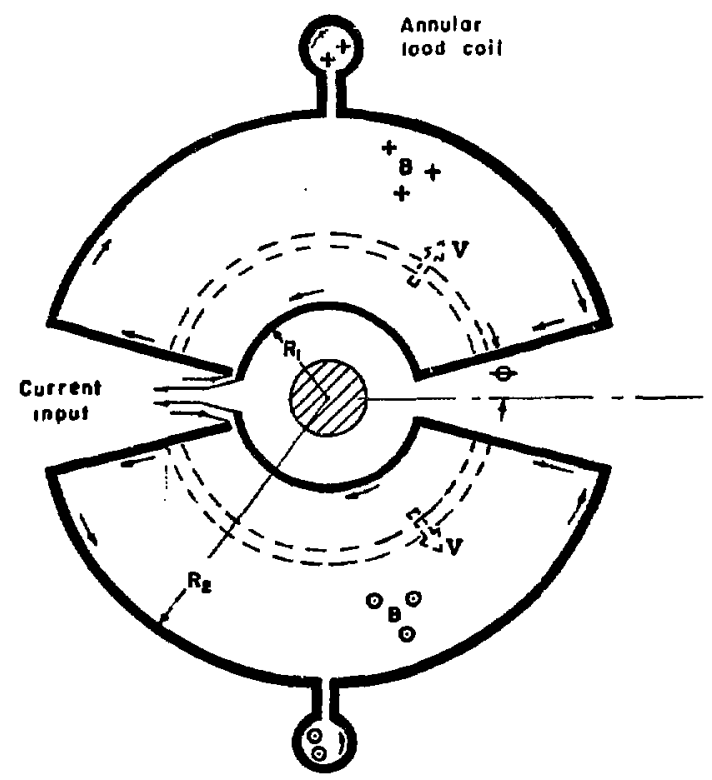

Fig. 8. Spherical generator schematic. The inner spherical sector is driven outward by the central explosive and serves as the armature. The external sphere is the stator and the annular ring connected to this sphere is the load coil. A later generation stage, after explosion, is shown by the new position of the armature indicated by dashed lines.

magnetic field lines are circular or tangential and are located symmetrically around the generator axis. Their directirns into and out of the diametral section shown in the figure are indicated by crosses and dots, respectively. The position of the armature part way through generator action is indicated by the dashed circular arcs. The fluxcompresion process is again evident.

The inductance of the generator depends upon the difference of the two spherical radii and upon the cone half-anclo. Denoting the stator and armature radii by $R_{2}$ and $R_{1}$, respectively, and the cone half-angle $r y \theta$, the inductance expression becomes:

$L=(\mu / \pi)\left(R_{2}-R_{1}\right) \log \left(\cot \frac{\theta}{2}\right)$ 
$L=0.4\left(\mathbf{R}_{2}-\mathbf{R}_{1}\right) \log \left(\cot \frac{\theta}{2}\right), \mu \mathrm{H}(\mathrm{MKS})$

As a specific example, when the cone half-angle is $0.1 \mathrm{rad}$ and the stator and armature radii differ by $1 \mathrm{~m}$ the inductance of the generator is $1.2 \mu \mathrm{H}$.

In common with the coaxial generators discussed earlier, this generator also has enormous current-carrying capability and has a particularly rugged construction. The spherical shape of the armature makes it attractive for use with nuclear devices, and also eases the problem of constructing a suitable debris containment vessfal if such is required.

\section{Initial Energy Sources}

As noted in Eq. (5), the energy output of a generator is proportional to the initial energy $\mathrm{E}_{\mathrm{o}}$ in thu generator. For this reason it is usually advantageous to load generators initially with the largest amount of energy possible. Generators are flux-compression devices and almost any source that can furnist the initial energy in magnet ic form is a potential source for the initial generator energy. Generators also work more efficiently against large magnetic fields and it is usually advantageous to have the initial magnetic energy also at reasonabiy high fields.

Primary energy sources are discussed in Sec. II. C. 1. The discussion is restricted to capacitor banks, inductive stores, and battery banks, alt hough for some low-energy devices other sources, such as ferroelectric and ferromagnetic materials, have application. Generators as intermediate energy boosting sources are treated in Sec. II. C. 2 .

1. Primary Energy Sources. Initial energy can be supplied to generators either by passing currents through them directly, thereby creating the initial magnetic fields, or by generating the fields in an external coil which surrounds the generato1. Capacitor banks are used almost exclusively as direct field eriergy sources, whereas external source coils may also be superconducting or battery-powered. a. Direct Feed. Previous illustra-

tions (Figs. 2, 4, 5, and 7) show leads from capacitor banks to the generators. The current discharge through the circuit upon switching in the capacitor bank follows the classical sinusoidal discharge represented by Eqs. (21):

$I=v_{0} \sqrt{\frac{C}{L_{T}}} \sin \omega t=\sqrt{\frac{2 \bar{E}_{O C}}{L_{T}}} \sin \omega t$

$P=2 \pi \sqrt{L_{T} C} ; \omega=1 / \sqrt{L_{T} C}$

$E_{o C}=\frac{1}{2} C V_{o}^{2}$

$\Phi_{O G}=L_{o} I=L_{o} \sqrt{2 E_{o C} / L_{T}}$

$E_{O G}=\frac{L_{c}}{L_{T}} E_{O C}$.

Here, $C$ is the capacitance of the bank, $v_{0}$ its charging voltage, $L_{T} r$ the total inductance of the circuit.

The period of the discharge is given by Eq. (21b) and maximum current occurs at the quarter period. As described earlier, generator detonation systems are timed to close off the current input supply at, or near, peak current and Eqs. (21d) and (21e) then give the initial flux and energy of the generator. After this time the capacitor bank is out of the circuit and Eqs. (21) no longer apply.

The presence of resistance in the circuit necessitates some modifications in Eqs. (21). Usually the effects are relatively small. Currents are normally reduced by $10-15 \%$ aldd initial generator energies by 20-30\%. However, in cases where the generator inductance is small it is imperative to keep the waste inductance terms small, as seen from Eq. (21e), otherwise much of the initial energy available from the capacitor bank will end up in source inductances. 
of $100 \mathrm{~kJ}$ are now relatively common. Generally speaking, installation and maintenance costs go up as the inherent discharge time of the bank is decreased. The inherent discharge time of a bank of given energy is reduced as the capacitance is decreased (which therefore requires a higher bank voltage), and also as the loss inductance terms are reduced. Such costs for fast banks can exceed by an order of magnitude those for a slower bank of the same energy. Within rather wide limits generator operation is relatively independent of the time required to supply the initial energy. Thus relatively slow banks of modest voltage are effective as initial energy sources--a considerable advantage from an economic viewpoint.

b. Indirect or Inductive Feed. Generators are initially energized inductively when the following difficulties are experienced:

(1) Perturbations that arise from explosive closure of the current input openings necessary for direct current feed are excessive,

(2) Initial capacitive storage is too heavy or bulky.

(3) Initial generator inductance is so low that the source inductance in the capacitor circuit stores too much of the available energy,

(4) Forces on the generator or load are too great with direct feed.

\section{(1) Elimination of Perturbations.}

An: assembled cylindrical implosion system and some of its components are shown in Fig. 9. The thin-walled cylinder, or liner, is of staildess steel with a thin inner cladding of copper. A capacitor bank introduces flux into the liner by energizing the coil pair straddling the explosive ring charge. The detonators have not yet been mounted on the charge. The absence of an input liner slot precltedes perturbations during explosive compression and the systram performs quite reproducibly. The energizing colls are sufficiently sturdy that initial magnelic ficlds of order $25 \mathrm{kG}$ can be induced within the liner.

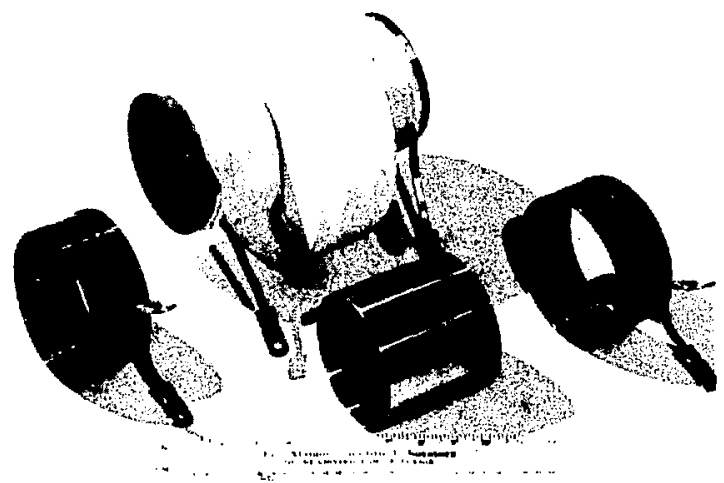

Fig. 9. Photograph of cylindrical flux-compression system components. The assembled system is shown at the top. Individual components shown include a coil pair and the thin-walled cylindrical liner. The ring of detonators has not yet been attached to the charge shown in the assembled system.

Compression fields of around 4 MG are obtained by implosion. Attempts to put more energy in these coils result in destrection of the coils by magnetic forces. When the energizing coils are wound of heavy welding cable they can sustain somewhat higher currents before destruc: ion and initial magnetic fields of 30-35 kG can be injuced in the liner. Compression fields of 5-6 MG can then be obtained. Efforts to sbtain still larger initial ficlds by means of cril pairs have led to other magnet ic force efreets which perturb the system. Hightr initinl fields. such as thase required to produce compression ficlds of 10 AIC or more. are now usually prefuced in a single coil which surresunds botis the lines ama the explostve system.

The arastare. or lines, is made of atain-

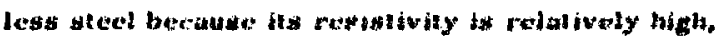
being some 30 times that of ropper. If the laner

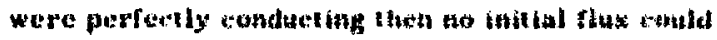

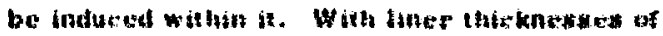

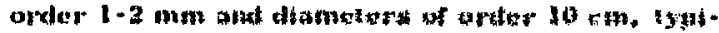

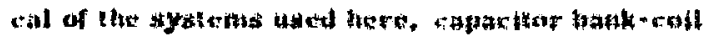

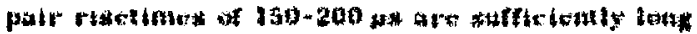


for aclequate flux penetration through the liner. On the other hand, the implosion time scale is more than an order of magnitude faster. Relatively good flux trapping then results during implosion because insufficient time is available for appreciable flux diffusion wut of the liner.

In some of the earlier cylindrical implosion systems the liners were slotted so that they could be energized directly by a capacitor bank. The liners could then be made of better conductors, such as aluminum or copper. Systems using these liners could produce compression fields up to 2 or $3 \mathrm{MG}$ in a fairly reproducible manner, but the performance became more erratic as the initial fields were increased to values necessary for production of higher compression fields. The orizin of the erratic behayior was traced to implosion perturbations caused by the liner slot.

\section{(2) Reduction in Size of Initial}

Energy Supply. Except ing water capacitors, which have a storage lifetime of only a few microseconds, capacilors are relativeiy bulky as energy stores. rypiral high - onergy density capacitors siore energy at a few tenths of a joule per cubic cemtineter and about $150 \mathrm{~J} / \mathrm{kg}$, whereas water caparitors can store a joule per cubic centimetey for a shov time. On the orher hand, a magnetic storage und with in field of about $30 \mathrm{kG}$ has a storage ene $z \mathrm{gy}$ densaly of 3.5

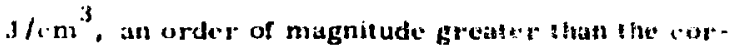
responding unit for high-energy density raparatore. similar gains can be obtained with incluctme stores: for the energy storage density per unit mass.

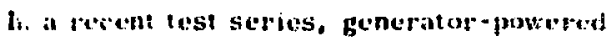
plasmal huts were roxke! - launched to alt ttudes of

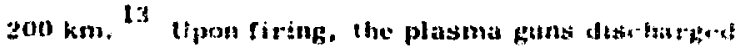

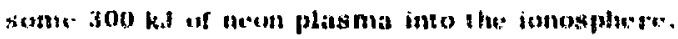

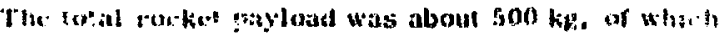
$230 \mathrm{~kg}$ was allowed row the genemat power stoply. Thus mass lamit was nuet, as wetwe at number of

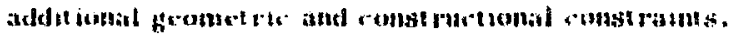

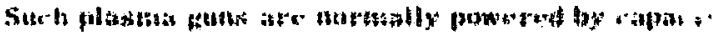

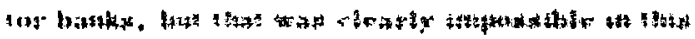

case since the bank and its associated circuitry would have required a mass of some $8000 \mathrm{~kg}$. Of the total power supply mass, $140 \mathrm{~kg}$ were required for the initial energy source, a small 16-kJ capacitor bank made of high-energy density capacitors. Some consideration has been given recently to a similar experiment in which comparable mass and size restrictions were placed upon the power supply but where plasma energies of a few megajoules were required. Results of early calculations ruled out a capacitor bank as the initial energy store because of the excessive mass and volume requir:d. On the othe: hand, inductive energy storage appeared quite feasible. An external solenoidal coil wound around the generator would be energized, thus supplying the initial magnetic energy to the generator. Two types of inductive stores seemed feasible: a high purity, cryogenically cooled aluminum coil, powered in flight by a bat tery bank; and a superconducting coil energized before launch. Partly because of scheduling problems, it was derided to restrict further investigations to the superconducting coil energy store. A sinall experimemal effort was undertaken to test use of this type of storage for generator applicatuous. At first glance it might appear unnecessary to lest stih isystem. However, there were some ubestions relat kert to the mutual coupling of the exfertual storage "osl to the generator during the oxplasive getleration stige. From the standpoint uf sulplytym: the Initual encegy to the generator. ight rupluge of the storage coil and generator is drstrably. laswerer, tdealized ralculations also show that unle'ss thas co.pling is redured near genroveng burnome much of the energy generated will

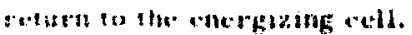

fingig: 10 shows the various generator com-

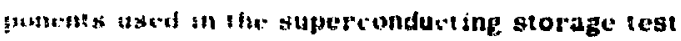
sterses. The sprtal soction of a small helical ger.er-

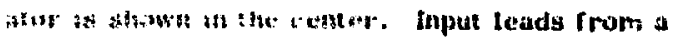

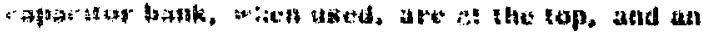

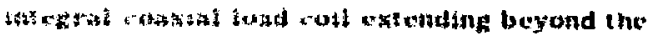




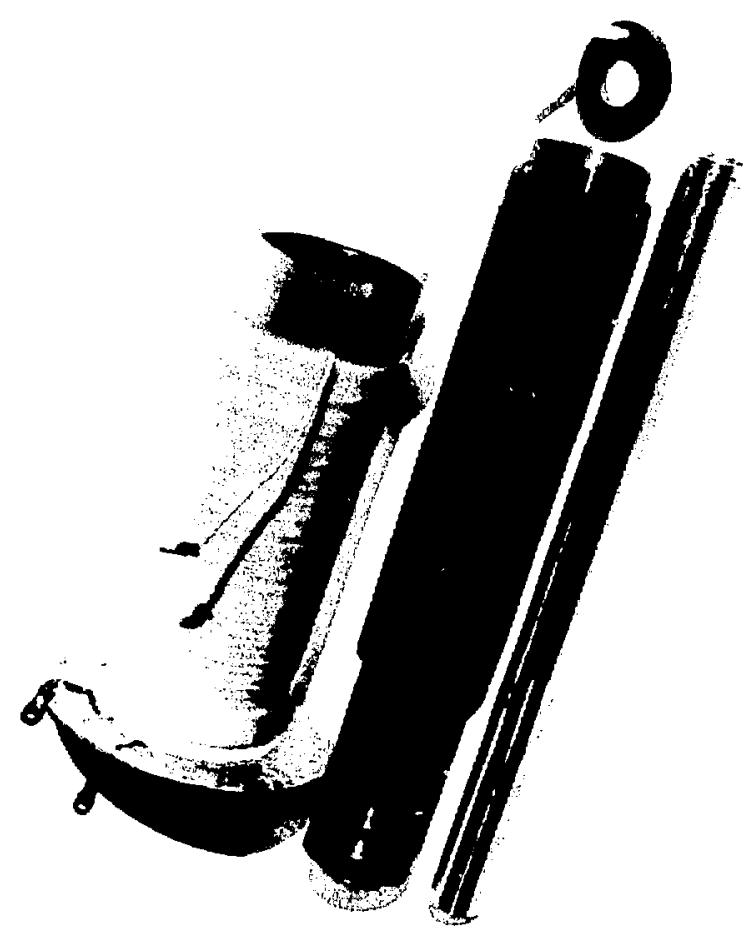

Eig. 10. Small-scale gene rator used in flux input tests. The spiral section with integral coaxial load is shown in the center. The thin-walled aluminum armature, loaded with cast cyclotol explosive, is shown at the right. Initial flux is introduced into the generator in several ways: by capacitor bank direct feed through cables bolted to the holes shown in both spiral and armature inputs; by inductive fetd through the capacitor bank powered coil shown at the left, into which the generator fits; and by a steady field produced by a superconducting coil shown in Fig. 11.

generator winding is seen at the bottom of this section. The generator armature, made of aluminum and loaded with cyclotol, is shown at the right.

Several identical generators of this type were fired with various sources of input energy, including direct feed with a capacitor bank, inductive feed through an overwound coil powered by a capacitor bank (as shown at the left in Fig. 10), and finally, indirect feed from a superconducting coil as shown in Fig. 11. The generator, whose outer diameter

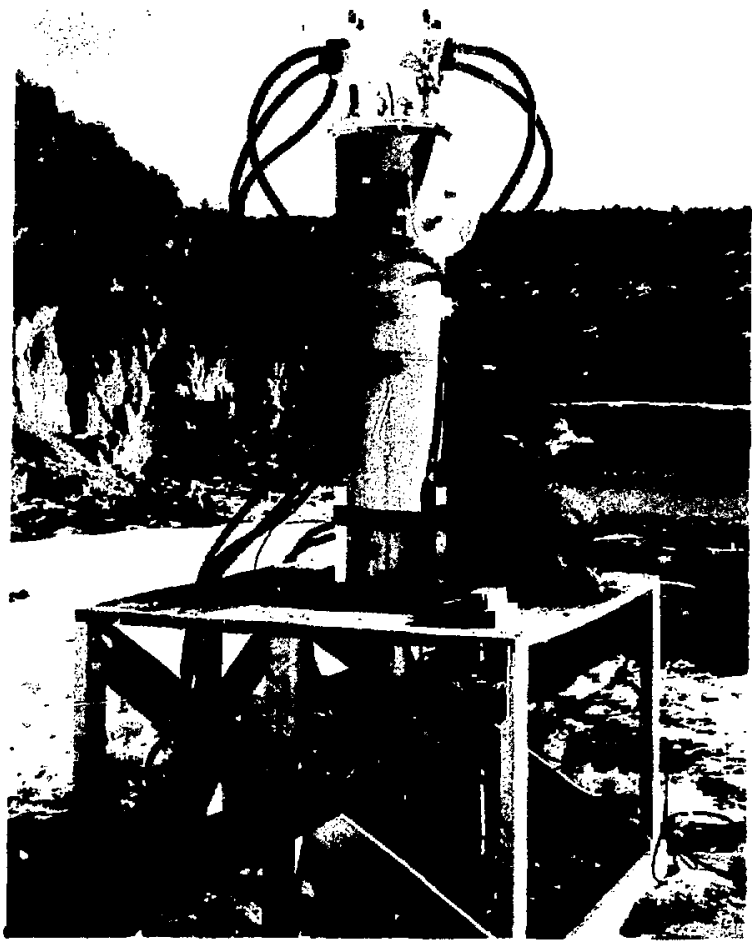

Fig. 11. Superconducting coil used as source of initial generator flux. Only part of the coaxial load section of the generator shown in Fig. 10 is visible, projecting below the superconducting coil system.

was only about $11 \mathrm{~cm}$, is just visible in Fig. 11 projecting from the bottom of the helium dewar which houses the superconducting $\mathrm{Nb}-\mathrm{T} i$ coil.

In all the tests an effort was made to supply about the same input flux to the generator. Relative generator performance for the various tests was gauged by the ratio of maximum output current iuto the coaxial load coil at generator burnout to the initial flux supplied to the generator.

The test results were quite satisfactory. The best results were obtained with superconducting energy storage and the worst with direct feed. The ratio of maximum generated current to initial flux for the superconducting feed test was som.e $15 \%$ greater than that for the direct feed test.

(3) Overcoming Source Inductances. Magnetic fields produced by direct current feed are 
usually closely confined to the current carrying elements, including those of the generator. In this sense such feed is efficient. This may be compared to indirect feed situations, such as shown in Fif. 9 for the cylindrical impiosion system feed where external coil pairs are used. Here, the bulk of the magnetic energy is located beneath the coils and not within the liner. In other words, the coupling is quite poor.' Indirect feed becomes more efficient than direct feed when the source inductance in the direct feed arrangement greatly exceeds the inductance of the generator. Such a case is illustrated schematically in $\mathrm{rig} .12$.

As pictured, the energizing circuit consists of a 100-kJ capacitor bank with a circuit source inductance of $0.1 \mu \mathrm{H}$. The low inductance of the single-turn solenoiclal load coil, $4.2 \mathrm{nH}$ (as calculated from Eq. (15a)), makes it unfeasible to energize it directly because of the large source inductance. As seen from Eq. (21e) only about $4 \%$ of the initial bank energy $E_{o C}$ gets into the load coil. As calculated from Eq. (21a) the peak current through the circuit is $I_{P K}=\left[2 \times 10^{5} /(0.1000+0.0042) 10^{-6}\right] 1 / 2$ $=1.39 \mathrm{MA}$ or $2.28 \mathrm{MA} / \mathrm{m}$ over the $61-\mathrm{cm}$ coil lengt $\mathrm{h}$. Magnetic fields in long solenoids are given by $\mathrm{B}=\mu \mathrm{J}$,

(a)

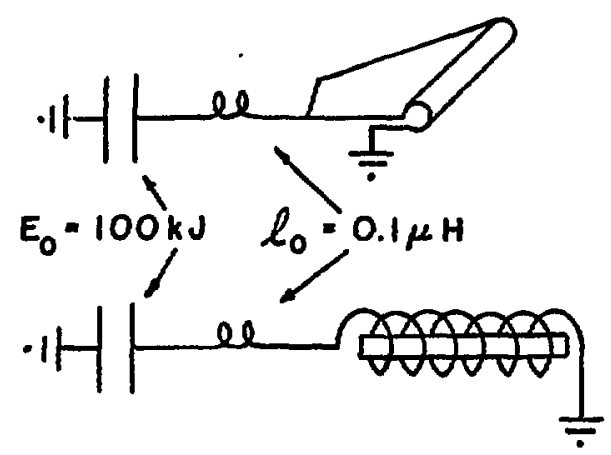

Fig. 12. Flux injection into a single-turn solenoid by direct feed (a) and by inductive feed (b). The single-turn solenoid has a radius of $2.54 \mathrm{~cm}$, and length $61 \mathrm{~cm}$. The multiple-turn solenoid has a radius of $3.05 \mathrm{~cm}$ and 61 turns are equally spaced over a length of $61 \mathrm{~cm}$. where $J$ is in amperes per meter. For this case the peak field becomes $B_{\mathrm{AAK}}=2.86 \mathrm{~W} / \mathrm{m}^{2}$ or 28.6 kG. The same analys is for case (b) of Fig. 12, where the coil inductance is $22.1 \mu \mathrm{H}$, gives $I_{P K}$ $=\left[2 \times 10^{5} /(0.1+22.1) 10^{-6}\right]^{1 / 2}=95 \mathrm{kA}$. However since there is $1 \mathrm{turn} / \mathrm{cm}$, the linear current density becomes $9.5 \mathrm{MA} / \mathrm{m}$ and the solenoidal field at peak becomes $B_{\text {PEAK }}=11.9 \mathrm{~W} / \mathrm{m}^{2}$ of $119 \mathrm{kG}$.

This example presents a rather extreme comparison because source inductances can usually be made considerably smaller than $0.1 \mu \mathrm{H}$ and the coupling of the single-turn solenoid to the multipieturn solenoid is somethat better than can usually be realized. Nevertheless many cases arise in which it is more profitable to energize inductively.

\section{(4) Reduction of Magnetic}

Forces. Magnetic fields exert forces on currentcarrying conductors and can be quite troublesome, not only on unsupported :onductors during the explosive or generation stage of a generator but also during the time in which the initial energy is introduced into the generator. These magnetic volume forces can be conveniently treated as pressures on the conducting surfaces given by Eqs. (22):

$P=\frac{B^{2}}{8 \pi}(C G S)$

$P=\frac{B^{2}}{2 \mu}$ (MKS).

Figure 13 illustrates both direct and inductive feed of the plate generator whose length is $\ell_{\text {, iaitial }}$ height $\lambda_{0}$, and width $w$ (perpendicular to the figure). In the direct feed case the magnetic field is essentially confined to the interior of the generator and all generator taces are subjected to magnetic pres sures which tend to force the plates outward. In case (b). the fields on both sides of the generator faces are equal. Although there are net compressive stresses on the generator plates, there are no net forces on the plates; consequenty there is no tendency for the generator to expand. 


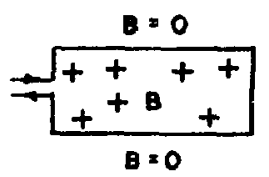

(a) Direct teed

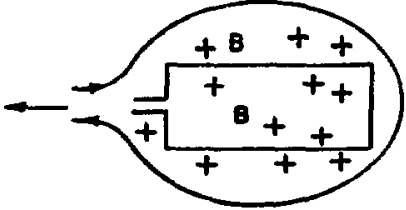

(b) Inductive feed
Fig. 13. Magnetic fields produced in and adjacent to a rectangular cross-section coil by direct current feed (a) and by inductive feed (b).

We can estimate the degree of motion of the top and bottom plates for the direct feed rase as follows. Let the areal density of the plates be $m$ grams per square centimeter, and suppose a peak magnetic field $B_{M}$ is built up in the generator in total time $T$. The field dependence on time is assumed to be of the form

$B(t)=B_{M}\left(\frac{t}{T}\right)^{n}$

When $n=1 / 2$, the field buildup approximates the sinusoidal time variation obtained by capacitor balk feed, while $n=2$ corresponds more closely to field buildups obtained from explosives generators. The pressure on a unit area of the $p^{\text {i }} i$ is is given by Eq. (22a) and the equation of motion on the plate bercomes

$n i i=\frac{B^{2}}{B \pi}=\frac{B_{M}{ }^{2}}{B \pi}\left(\frac{t}{T}\right)^{2 n}$.

The plate displacement $\Delta_{x}$ at time $t$ becomes

$\Delta x=\frac{B 1^{2}}{8 \pi m} \cdot \frac{1^{(2 n+2)}}{r^{2 n}(2 n+1)(2 n+2)}$

and the displacement at $B_{M^{*}} t=T$. becomes

$\left(\Delta_{v}\right)_{1}=\frac{\mathrm{B}_{\mathrm{M}}^{2}}{\mathrm{Bm}} \quad \frac{T^{2}}{(2 n+1)(2 n+2)}$
As an example, if the plate areal density is 1 $\mathrm{gm} / \mathrm{cm}^{2}$ (somewhat more than $1 \mathrm{~mm}$ thick for copper) and a peak field of $1 \mathrm{Cn} \mathrm{kr}$; is obtained in $50 \mathrm{\mu s}$ from a capacitor discharge, the plate is displaced about $1.7 \mathrm{~mm}$ when the field reaches $100 \mathrm{kG}$.

Such a displacement is intolerable for most systems. In the case of the plate generator, additional explosive mass rests on top of the upper plate and this increases the effective mass by perhaps an order of magnitude. Even so, the resulting displacement of $0.17 \mathrm{~mm}$ is still serious for some applications. It is clear from Eq. (26) that the displacement is less serious if the time $T$ can be reduced. For example, of two capacitor banks of equal energy but different capacitances, the one of smaller capacitance would deliver its energy to the coil in a shorter time and there would be less plate displacenient.

Another way of combatting the displacement problem is to sacrifice some initial flux in the generator by firing it before peak field is reached. $T$ i:us from Eq. (23) when $n=1 / 2,90 \%$ of the $\max -$ imum flux is reached when $t=0.81 \mathrm{~T}$. Substitution of this time in Eq. (25) shows that the displacement at that time is only about $0.9 \mathrm{~mm}$ instead of the 1. $7 \mathrm{~m}$ m obtained at peak flux. The small sacrifice in flux is usually worth accepting to realize the significant decrease in generator component dis placements.

\section{Generators as Intermediate Energy}

Boosters. Generators are frequently used as intermediate energy boosters (Fig. 14).

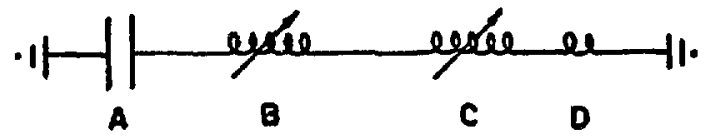

foig. 14. Cirruit schematic of a system that employs a series booster generator $B$. This gerierator boosts the initial energy stored in the capacitor bank $A$ to a higher value which then serves as the initial energy for thi output generator $c_{\text {, }}$ which finully encreizes load $D$, 
Generally speaking, the type of output generator $\mathrm{C}$ required is determined by the characteristics of the load D to be energized. Two situations arise frequently in which it is not feasible to power the major output generator directly from the primary energy source $A$. First, the primary energy source may store less energy than required to energize the output generator. Second, the magnetic forces generated during initial energy buildup in the output generator by direct feed may be too disruptive. The following examples illustrate these points.

\section{a. Energy Boosting: Figure 15 shows} a shot assembly on the firing table. The assembly includes an energy boosting generator. The subsequent shot was one of the preliminary tests leading to the development of the power supply used in the rocket-launched plasma gun experiments mentioned earlier, in which the primary energy source was a 16-kJ capacitor bank. The vertical coaxial load coil, shown at the right, had an inductance about equal to that of the average plasma gun inductance (which actually varied with time during discharge). The cables coming from the top of the load coil were connected to field measuring probes.

The output, or major, generator connected to the load coil is shown in the center. It is a

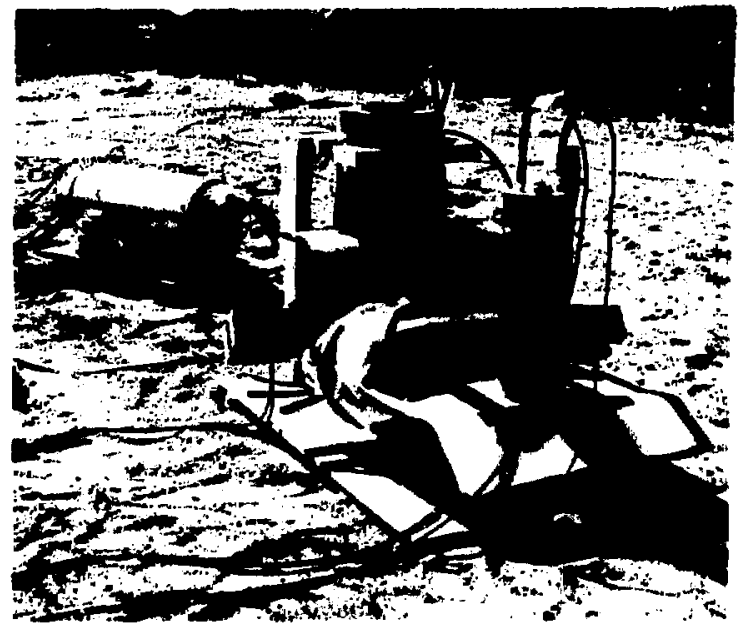

Fig. 15. Shot setup with a series booster generator. relatively low inductance spiral generator capable of carrying several megamperes and supplying several hundred kilojoules into the plasma gun load. provided initial input energies of 60-75 $\mathrm{kJ}$ are available. Since only $16 \mathrm{~kJ}$ were available in the capacitor bank, the spiral generator shown at the left (positioned horizontally) was designed to boost the energy to about $75 \mathrm{~kJ}$ as initial energy for the major generator. The major generator was also a spiral gevelator with low initial inductance and relatively high current-carrying capacity. Leads from the initial capacitor bank energy source enter the booster generator frorn the left. The output of the booster generator is connected to the input of the major generator by coaxial cables. The major generator was not detonated until booster generator burnout. During the booster generating stage, the major generator functioned as a load coil.

In the arrangements shown in Fig. 15 and in Fig. 16, which is discussed later, the booster generators are series-connected to the output generator. It is also possible to energize output generators inductively by means of booster generators, although it was not practicable for the rocketlaunched power source.

\section{b. Force Reduction. Equation (26)}

gives an approximate expression for generator component displacement when a peak magnetic field $B_{M}$ is reached in a time $T$.

The displacement depends strongly on the time history of the field rise to peak. Equation (26) was derived under the assumption that the magnetic field increased to peak according to Eq. (23), where the sinusoidal field rise produced by

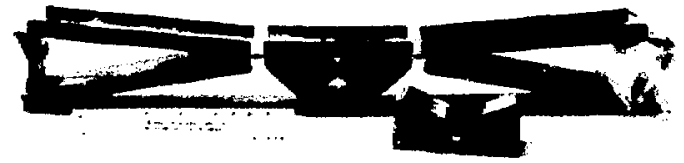

Fig. 16. Two-stage atrip-plate generator. 
capacitor banks was approximated by using $n=1 / 2$ in the equation. On the other hand, the field buildup from many explosive generator sources is fairly well approximated with a value of $n=2$. Accoraing to Eq. (26), the component displacement suffered from capacitor bank energization would be five times as great as that obtained from generator energization to the same field $B_{M}$ in time $T$.

The above discussion is only qualitative, but the principle involved is quite real and in many cases minimization of component displacements is crucial. Figure 16 is a photograph of a two-stage generator system illustrating this principle. The system consists of two series strip generator boosters, the triangular channeled sections, an output plate generator and a load coil. The cylindrical load coil and plate generator cavity are formed from the large central brass wedge. The strip generator explosive (not shown) consists of strips of sheet explosives placed in the four channels of the triangular sections. The plate generator explosive system consists of a separate piece of $\mathrm{HE}$, together with a plane wave lens. They are placed upon the channeled flat section over the triangular wedge cut out of the brass block. The sequence of operations is as follows: Initial energy is supplied to the entire assembly from a capacitor bank through the input slot at the top. At peak flux, the shect explosives are detonated at the far ends of the triangular strip generators. After closure of the input current slot, detonation proceeds and flux is pushed into the plate generator and load cavities. The plate generator explosive is detonated at such time that the top plate starts compressing the flux in the wedge-shaped cavity upon burnout of the st rip generators.

This system was first developed to produce high magnetic fields in the load coil. Initial fields produced by the capacitor bank were about 75 kG, the maximum value the system could withstand without excessive structural distortion from magnetic forces. The strip generator action increased this field to about $375 \mathrm{kG}$ as the starting field for the plate generator stage. Again, fields higher than this value produced too much displacement of the top plate. Final fields of around 2 MG were produced in the load coil at plate generator burnout.

A number of investigators have used spiral generators as boosters for coaxial generators, and Sakharov et al. ${ }^{5}$ have developed a system in which a spiral generator is used as a booster for a cylindrical flux-compression system.

D. Techniral Aspects of Generator Technology Switching and pulse shaping generator outputs in direct load-feed situations are discussed briefly in Sec. II. D. 1. Use of transformer coupling to extend the range of impedances capable of being energized by a generator is treated in Sec. II. D. 2 . Various generator limitations are discussed in Sec. II. D. 3, and it is shown that high-energy direct feed of large inductive storage units by a generator is not feasible. Section II. D. 4 p.esents idealized calculations which show that such inductive storage units can be energized through transformer coupling.

1. Switching and Pulse Shaping. It was mentioned earlier that, subject to conditions dealing with the nature of the single output pulse, generator outputs can often be handled in ways customarily used with more conventional electrical sources.

The output of a spiral generator used in the $\theta$-pinch experiments of Refs. 9 and 10 was sharpened by means of a nonlinear fusing element sc that an initial high-voltage spike could be placed around the $\theta$-pinch coil. The experimental. setup used is shown schematically in Fig. 17. The generator burnout time was about $40 \mu \mathrm{s}$. Because of its relatively short length, the $\theta$-pinch plasma could be subjected to magnetic compression for only a few microseconds. To make the plasma conducting, and therefore magnetically compres." sible, it was also necessary to put a high-voltage 


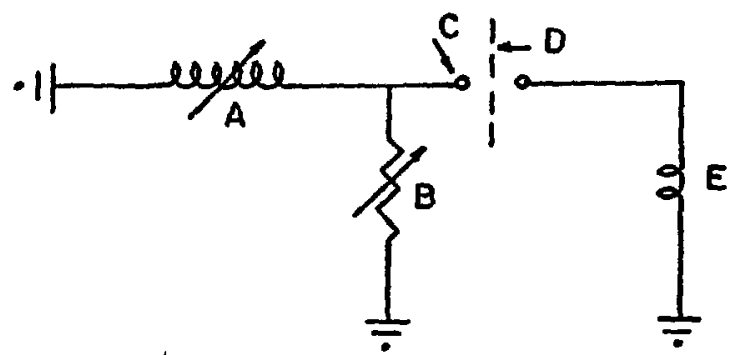

Fig. 17. Generator A, with nonlinear fuse element $B$. The fuse is so designed that the dielectric insulator $D$ breaks down across the spark gap $C$ at a prescribed voltage and time during the generation stage, thus switching load $\mathbf{E}$ into the system.

pulse around the $\theta$-pinch coil before subjecting it to the magnetic compression fielc. This was accomplished by the combination of pulse shaping and switching indicated by elements B, C, and D. Element $\mathbf{C}$ was a spark gap switch set to break down at a specified voltage, determined by the pretested breakdown strength of the dielectric insulasor $D$. Element B was a carefully constructed resistive fuse designed with low initial resistance and constructed in such a manner that it vaporized (thus leaving the circuit) not only at the voltage necessary to break down the spark gap, but also at an appropriate preselected time during energy generation. Owing to the nonlinear character of the fuse, the generator out 'ut pulse was considerably sharpened but at a significant cost in energy.

The rocket-launched plasma gun experiments furnish examples of active switching, and also demonstrate that highly complex generator systems can be made to work reproducibly. The schematic of the system actually used is shown in Fig. 18. The initial energy source was a small $16-\mathrm{kJ}$ capacitor bank. A booster genorator increased this energy to a value suitable for the initial energy of the lower inductance output generator. The plasma gun was switched into the circuit rather late in the output generation stage. Before this time the generator circuit was completed by a ballast load coil shown in the figure. All switching was accomplighed by

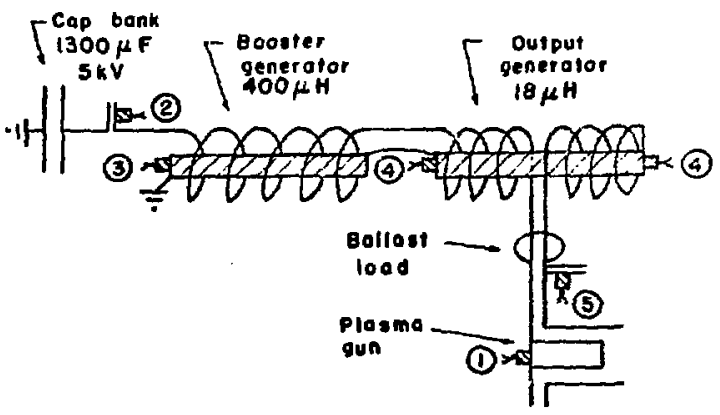

Fig. 18. Schematic of rocket-borne generatorpowered plasma gun system. Detonators were fired sequentially to actuate the plasma gun neon valve (1), switch in the capacitor bank (2), initiate the booster (3) and output generators (4), and to switch in the plasma gun (5).

detonators. The neon plasma gun was pulse-loaded. The first detonator fired actuated a mechanism to release neon to the plasma gun. Switch 2 connected the capacitor bank to the two generators and bailast los. The third detonator fired the booster generator which then increased the energy flow into the output generator. The detonators for the out?-ut generator were then initiated. Finally, at the appropriate time, switch 5 was fired and the plasma gun was coupled into the circuit.

The shot assembly of Fig. 15 shows the two generators used in these experiments, together with a simulated plasma gun load coil. The plasma gun is isolated from the output generator by a detonat or activated switch, clearly visible. The detonators are obscured. The vertical circular ring just in front of and to the left of the coaxial load coil serves as the ballast load coil. It is connected to the parallel transmission line just ahead of the detonator switch plates.

The final packaging of the various components into the rocket payload was largely the responsibility of Sandia Laboratories. Final tests of the payload before actual launch were carried out on the firing table, as were all the preceding development shots leading to the final design. Figure 
19 shows the shot setup for one of these tests. The payload was inverted to make it easier to dia nose the neon plasma. (The plasma gun was mounted in the aft section of the payload.) In this test, all operations were carried out by telemetry command. A complete assembly, including both payload and rocket, is shown mounted on the launcher in Fig. 20. I hree experiments were carried out and all were successful. Details of the generator development program, from conception to launch, may be found in Ref. 13 .

\section{Use of Transformers. In the gen-} erator exainples considered so far, the loads to be energized have been fed directly by the generators. Further, they have been essentially low inductance

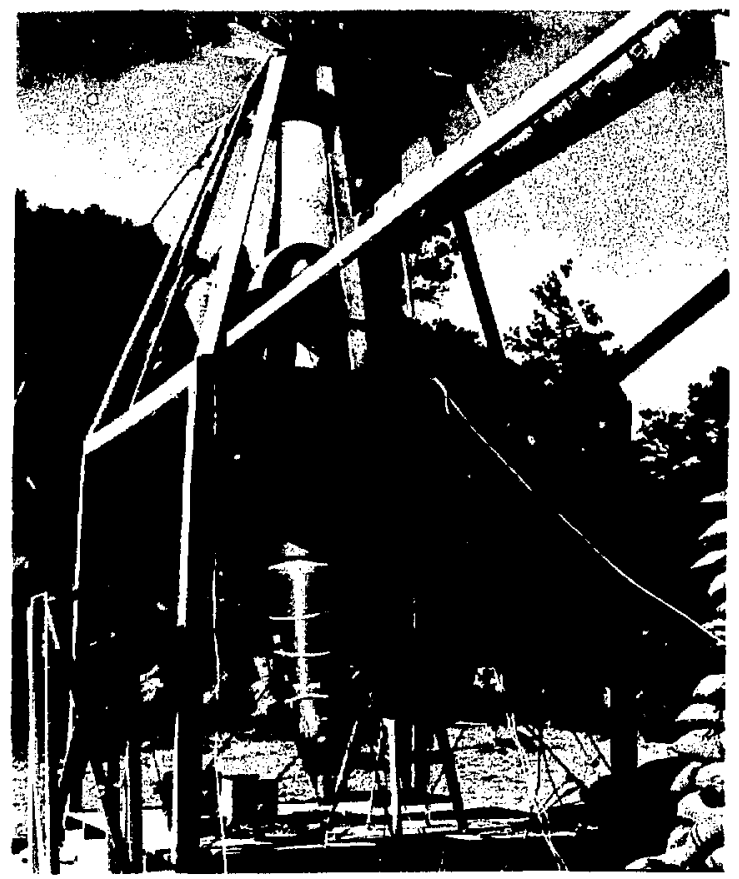

Fig. 19. A generator-powered rocket-borne plasina gun test shot on the firing table. Aside from the components indicated schematically in Fig. 18, the payload housed an on-board capacitor bank charging supply, detonator timing and firing units, telemetry command receivers and transmitters to telemeter various diagnostic signatures.

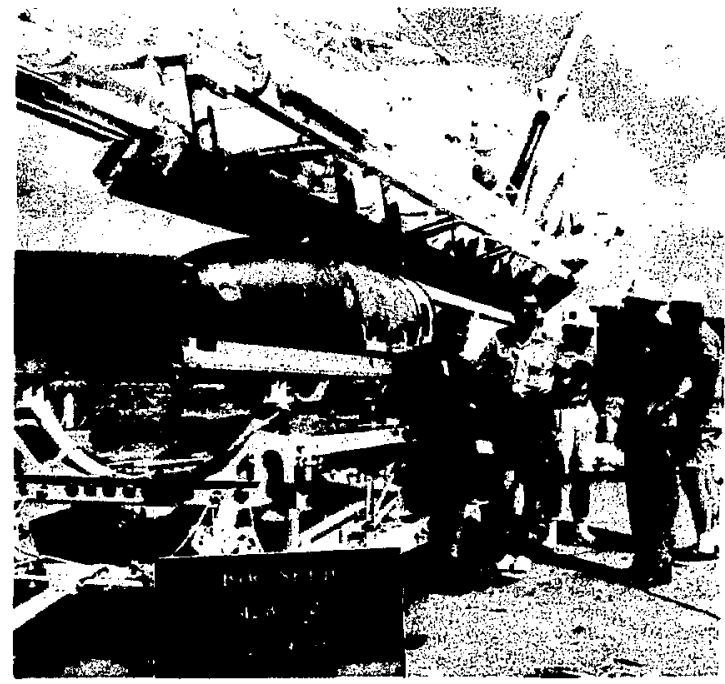

Fig. 20. Complete assembly on the launch pad, showing the rocket and payload which houses a generator-powered plasma gun.

loads. Circuit resistances, although briefly discussed, have been treated as unavoidable loss ternis. The reason for using low inductance loads follows from $\mathrm{Eq}$. (5), which shows that load energy multiplication variess inversely with the load inductance.

Generator currents are attenuated when resistance is in the circuit, as shown generally by Eq. (6) and by Eq. (9) when the generator inductance has the form of Eq. (8). The energy absorbed by the resistance $\mathbf{R}$ at generator burnout can be calculated for this case from $\mathrm{Eq}$. (9):

$$
\begin{aligned}
& E_{R}(\tau)=\int_{0}^{T} I^{2} R d t \\
& =2 E_{0} \frac{R T / L_{o}}{1-2 \frac{R T}{L_{0}}}\left[\left(\frac{L_{0}+L_{1}+\ell_{0}}{L_{1}+l_{0}}\right)^{1-2 \frac{R T}{L_{0}}}\right] .
\end{aligned}
$$

Here $E_{0}$ is the initial inductive energy in the circuit, $1 / 2 \mathrm{I}_{0}{ }^{2}\left(\mathrm{~L}_{\mathrm{o}}+\ell_{\mathrm{o}}+\mathrm{L}_{1}\right)$. In the present context, 
$E_{R}(\tau)$ is an expression for energy lost to the resistance, but there are situations where it would be desirable to energize resistive loads such as laser cavities. In this case, large multiplications would be desirable. Unfortunately, the maximum resis tive energy gain occurs under the following conditions:

$R \tau / L_{0}=0.5$

$E_{R}(\tau)_{\max }=E_{0} \log \left[\left(L_{0}+L_{1}+\ell_{0}\right) /\left(L_{1}+\ell_{0}\right)\right]$

The logarithmic dependence on the inductance ratio so restricts energy gains into a resistance load that there are very few cases where it is favorable to directly energize a resistance by a generator.

These examples have led to the rather widespread misconception that explosive generators are suitable only for powering low inductance loads.

This is true for the direct feed applications discus sed so far. However, when transformers are used to couple to low inductance loads, into which generators operate more efficiently, it becomes possible to energize a wide range of impedances with generators. These impedances can include resistive loads as well as loads with inductances far greater than the inductance of the generator itself. Figure 21 shows schematically a generator system with transformer coupling to an inductance load $\mathrm{L}_{3}$ which is to be energized.

The primary circuit consists of the generator, a source inductance, and primary load coil $L_{1}$. The secondary circuit consists of the load $L_{3}$ to be energized and a transformer coil of inductance $L_{2}$. The mutual inductance between $L_{1}$ and $L_{2}$ is denoted by $\mathbf{M}$. Switching is provided in the secondary circuit at arbitrary time $\tau$.

For demonstadtion purposes the circuits are assumed to be nonresistive. In this case, flux is conserved in both circuits. Prior to switching in the second circuit, current $I_{1}$ flows only in the

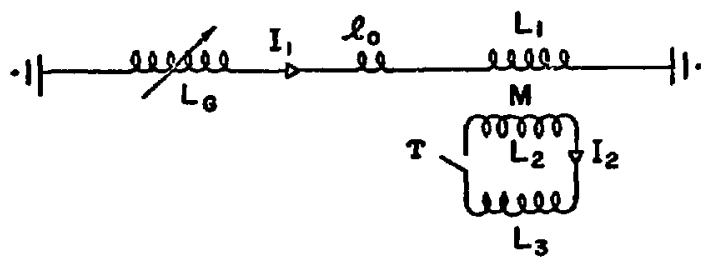

Fig. 21. Schematic of circuit that shows how a generator is used to power a load $\mathrm{L}_{3}$ through transformer coupling to the primary generator load coil $\mathrm{L}_{1}$.

primary, and the initial flux in the secondary circuit is obtained only inductively. If the generator inductance is denoted by $\mathrm{L}_{0}$ at switch time (now taken as $t=0$ ) the circuit equations (from flux conservation) reduce to:

$\left(L_{G}(t)+\ell_{0}+L_{1}\right) I_{1}+M I_{2}=\left(L_{0}+\ell_{0}+L_{1}\right) I_{0}$

$M I_{1}+\left(L_{2}+L_{3}\right) I_{2}=M I_{0}$

$M^{2}=k^{2} L_{1} L_{2}$

Equations (29a) and (29b) can be solved algebraically for the currents. At generator burnout, $t=\tau$ and $L_{G}(\tau)=0$, the secondary current $I_{2}$ becomes:

Burnout: $I_{2}=\frac{-M L_{o} I_{o}}{\left(L_{2}+L_{3}\right)\left(L_{1}+\ell_{o}\right)-M^{2}}$.

Generally speaking, the coupling coefficient $k$ of Eq. $(29 \mathrm{c})$ is made as large as possible. For a given coupling coefficient, there is an optimum value of $\mathrm{L}_{2}$ to get maximum secondary current and thus energy into $L_{3}$. From Eq. $(30)$ this value is found to be:

For $I_{2}(\operatorname{MAX}): L_{2}=\frac{L_{3}}{1-k^{2} \frac{L_{1}}{\frac{l_{0}+L_{1}}{2}}}$. 
Under this condition the current and energy at burnout become:

$$
\begin{aligned}
& I_{2}=-\frac{k}{2} I_{0}\left[\frac{L_{1} L_{0}^{2}}{L_{3}\left(l_{0}+L_{1}\right)\left(\ell_{0}+L_{1}-k^{2} L_{1}\right)}\right]^{1 / 2} \\
& E_{3}=\frac{k^{2}}{8} \frac{L_{1} L_{0}{ }^{2}{ }_{0}^{2}}{\left(l_{0}+L_{1}\right)\left(\ell_{0}+L_{1}-k^{2} L_{1}\right)} \\
& \vdots \frac{k^{2}}{4} E_{0} \frac{L_{0}}{L_{1}+l_{0}}-\frac{L_{1}}{\ell_{0}+L_{1}\left(1-k^{2}\right)}
\end{aligned}
$$

The initial energy in the primary circuit is given approximately by $1 / 2 L_{0} I_{0}^{2}$. The energy delivered to $E_{3}$ is thus seen to be independent of the load induclance $L_{3}$. As it turns out, the energy maximum is not sharp and a fairly wide range of vilues of $L_{2}$ around the value given in $\mathrm{Eq}$. (31) still allows delivery of substantial energies to $L_{3}$. Interestingly enough, for very tight trans forner coupling, k near 1, Eq. (32b) shows that more energy can be delivered to a load of arbitrary undatance $L$, through transformer coupling than would be delivered by the generator to the unloaded primiry roul itself. This situation also requires that the source inductance term $\ell_{0}$ be con'siderably smaller than the load coil inductance $L_{I}$. This fattcr andition can usually be met. In our experin'nce, furwever, it is not possible to obtain the tight 'rupling relqured to achieve this objective.

Extension of the example to account for cir'uit resistinces leads to equations that require numerical techniques for solution. Results show that with proper thoice of transformer parameters other loads, such as capacitors and resistances, cun also be energized effectively with generators.

Figures 22, 23 and 24 have been extracted from a Los Alamos report to ARPA. 14 Figure 22 shows the unassembled components used in making a two-sided sirip generator (upper left), the system partially assembled (lower left), the complete unloaded assembly (upper right), and finally the loaded assembly on the firing table, with a transformer in place in the primary load coil the cylindrical cavity in the slotted brass block). Figure 23 shows one of the transformers used in a shot series, and Figure 24 shows a recovered transformer after a shot. Such small generators and transformers have delivered several tens of kilojoules into capacitive loads, resistive loads (up to several ohms), and inductive loads (up to $30 \mu \mathrm{H}$ ). The initial generator industance is $0.25 \mu \mathrm{H}$ and the primary load inductance about $25 \mathrm{nH}$. Transformer inductances varied from a few to a few tens of mic rohenrys.

A larger spiral generator and transformer have delivered nearly $300 \mathrm{~kJ}$ to a resistance of several ohms.

Aside from the wide range of impedances that can be energized successfully, transformer coupling is of great value in high-voltage management. For high-voltage applications, the burden of voltage standoff can be placed upon the secondary circuit instead of the generator. With adequate insulation, megavolt potentials are attainable across secondary impedances. Few generators have a sufficiently high value of $\dot{L} I$ (see the discussion of Eq. (14)) to generate megavolt potentials, and none developed to date, to our knowledge, could withstand such internal voltages even if they could produce them.

\section{Generator Limitations. Good gener-} ator technology is governed by a number of factors. Because explosives generators destroy some systems components their use is limited to single shot or, at best, low repetition rate applications. Also, in many cases they are expensive to construct. Finally, ildditional safoty precautions must be taken over those required for more conventional power sources to guard against explosive hazards. For these reasons there must be compelling advantages to justify their use. 

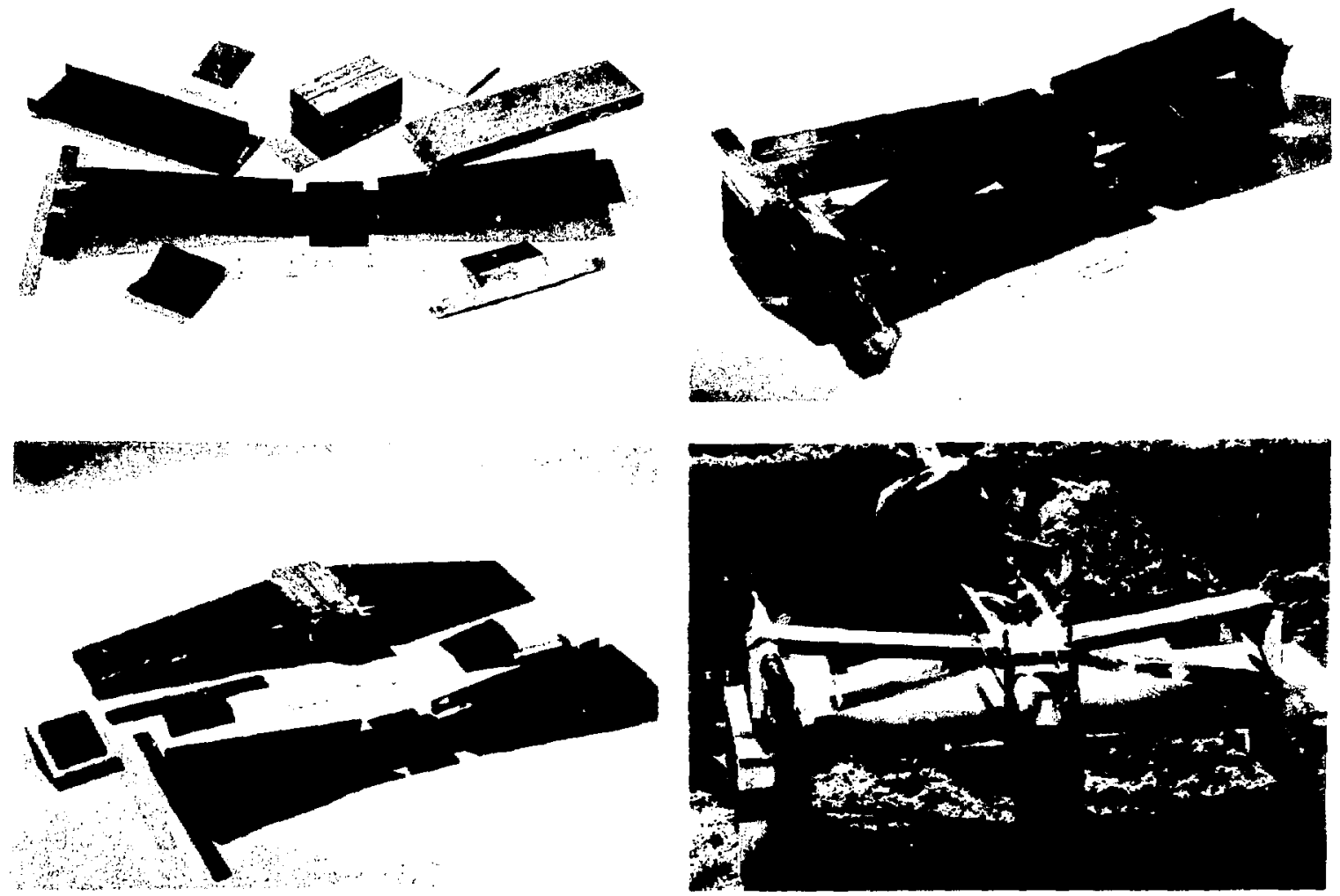

Fig. 22. Views of a double-ended single-stage strip generator in various stages of assembly. The lower right view shows the completed generator with explosive and secondary coil in place ready for testing.

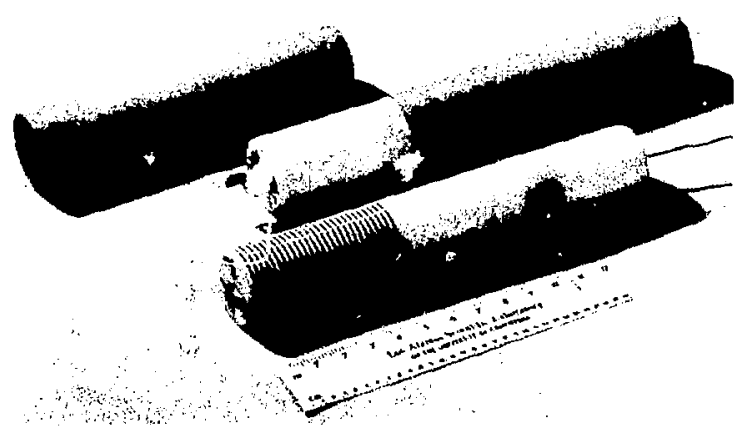

Fig. 23. Secondary coil for double-ended, singlestage strip generator. No. 17 enamelcoated copper wire is wound on a polyethylene form at about 2 turns $/ \mathrm{cm}$.

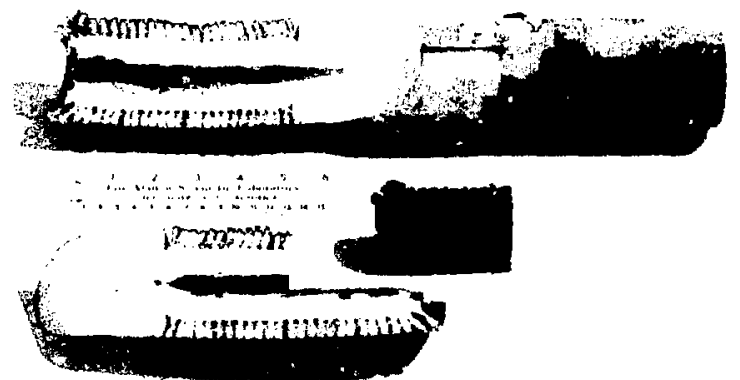

Fig. 24. Secondary coil of the type shown in Fig. 23 recovered after firing and sectioned to show the winding penetration into the polyethylene coil form. The windings have penetrated over $9 \mathrm{~mm}$ into the core. 
These advantages do exist. Among them is the capability of producing enormous energy bursts in time scales not normally available otherwise. Further, unlike caparitor or inductive storage units, generator designs can be readily modified to allow them to meet changing load requirements. Again, unlike capacitor discharges, generator output voltages and currents have large time regions where they are approximately in phase. For some applications this can be a decisive advantage. Other advantages arise fro- heir extremely high ratio of energy output to weight and volume.

Ideally, the type of generator required is governed strongly by the type of load to be energized. If the currents required are not excessive and the time scale of the experiment is not too short, spiral generators are probably best because of their inherently large energy multiplication. Coaxial, strip, and spherical generators are well suited to power loads where large currents are required but where the experimental time scale is nut tos short. Plate generators are sapable of ('arrying very large currents and can operate on substantially faster time scales. Cylindrical fluxrumpression systems are used when very intense nagnetic: fields are required. If they can be used to drive transformers, they have the capability of powering external loads on still shorler 1 ime scales.

Economic factors also play a role in generator selection. Strip generators are relatively inexpensive because the fabrication of both the metal components and the ...illosive system are simple. Plate generators and cylindrical implosion systems rexuire expensive explosive initiation systems, but the rest of the explosive system and the metal fabrication are relatively simple. The helical section of a spiral generator is expensive to fabricate but the explosive system is simple.

A number of other technical factors must also be considered. These include: minimizing suurce or loss inductance terms; minimizing unwanted motion of system components by magnetic forces, botn during introduction of the initia, energy and during the energy generation stage; minimizing or eliminating metallic jets which are often formed at contacts between metal structures in relative motion; keeping flux losses to a minimum during the generation stage; and preventing internal voltage breakdown inside the generator.

While these factors are important in any generator application, three of them are of special significance in the present study in that they rest 1 ict : he classes of generators that can be used. These factors deal with flux losses, high magnetic field effects, and internal voltage breakdown, and are treated in the following sections.

\section{a. Flux Losses. Flux losses are} easily understood for some mechanisms. Pocket ing of flux by alternate sonducting paths arising from internal breakdowns or premature closure of part of the flux-compression legion are examples. Resistances in the circuit cause some flux loss by reducing the magnitude of current generated. Unrecover"' le flux is also trapped in the conducting layers of the generator components.

A reasonably good accounting of these losses can be made for most gene rators, provided the current density does not greatly exceed $1 \mathrm{MA} / \mathrm{cm}$. Helical generators usually are anomalously lossy. even when they are thought to be free of flux pocket ing. When theoretical predictions are forced to fit experimental data by adjustment of the generator resistance, the resistances so calculated are usually far higher than can be accounted for. We think part of this difficulty can be traced to armature performance. A comparison of the arm:: ire requirements for a spiral and coaxial generator can be made by comparing the upper sketches of Figs. 2 and 7 . The armature dynamics in both cases is similar. In both cases generator currents are carried axially by the armature. However, in the spiral configurations the initial flux is given essentially by axial fields arising from the helical currents, as opposed to the flux in the coaxial 
generator which arises from purely tangential or circular magnetic fields. Flux compression in the spiral generator therefore requires generation of circular eddy current; sound the armature for rnagnetic field buildup within the space between the spiral and helix. One explanation that would account for the relatively large losses in spiral generators is as follows: If the armature were to suffer axial cracking or other significant axial strains, these might lead to anomalously high resistance for the tarigential eddy currents, but would have only minor influence on the resistance to axial current flow.

In general, it has become customary to characterize helical generator performance by a figure of merit, ${ }^{6}$ which accounts for all flux losses in an approximate way. The figure of merit $\alpha$ is defined by:

$$
\left(\frac{I}{I_{0}}\right)_{\exp }=\left(\frac{I}{I_{0}}\right)_{\text {th }}^{\alpha}=\left(\frac{L_{0}}{L}\right)^{\alpha}
$$

Here $\left(I / I_{o}\right)_{\exp }$ is the maximum abstrved experimen$x$ al current ratio, and $\left(I / I_{0}\right)_{t r}$ is the predicted ratio under perfect thux compression. $L_{b}$ is the total initial circuit inductance, and $L$ the final circuit inductance.

The actual energy multiplication ratio also follows from Eq. (33):

$\frac{\frac{1}{2} L_{I}^{2}}{\frac{1}{2} L_{0} I_{0}^{2}}=\frac{E}{E_{0}}=\left(\frac{L_{0}}{L}\right)^{2 \alpha-1}$.

Strictly speaking, values of $\alpha$ are determined only at burnout conditions, and a constant value of $\alpha$ is not expected to characterize the generator performance throughout its entire generation period. How ever, a qualitative guide to generator performance can be obtained by assuming that Eq. (33) holds throughout the generation period. Our experience shows that higher values of $\alpha$ (occasionally greater than 0.9) are experienced only when the generator diamet ars are large, coil tur. a are wide and also spaced widely, theoretical multiplıcation factors are not too large, and current densities are reasonably small (less than $1 \mathrm{MA} / \mathrm{cm}$ ). Lossless performance is obtained when $\alpha=1$ and, at the other extreme, no energy gain 1 'esults when $\alpha \leq 0.5$. Ordinarily an $\alpha$ of 0.85 is exceptionally good, 0.75 to 0.80 is average, and less than 0.7 is rather Foor, but these values can be modified considerably when the initial inductance ratio is large. For example, if the initial inductance ratio were 5000 , even with an $\alpha$ as low as 0.70 , there is an energy multiplication of 30 , a value far from the lossless ratio of 5000 but still impressive.

b. High Magnetic Fieid Efrects. As already stated, current densities in excess of 1 MA/cm frequently result in degradation of generator performance. Current densities of this magnitude generate megagauss fields at the surface of the conductor. More precisely, a field of $4 \pi / 10$ MG is generated when the current dersisty is 1 MA/cm. These magnetic fields interact $w$ ith the conductor in two ways. They subject the conductor to pressure $\mathrm{B}^{2} / 8 \pi$, and they deposit energy in the conductor. The necessity to counteract the pres sure forces has been discussed earlier. Generally speaking, it is imposbible to generate fields in excess of a few megagauss in volumes that are confined only inertially. Axial fields in excess of 3 MG have so far been produced only in systems that are confined by explosives, as in the cylindrical flux-compression system. Even in this case. as peak rields get higher the field pulse width must ge: narrower. Presumably, inertial confinement systems will be capable of sustaining larger peak fields than presently achieved if means can be developed to get the energy into the load coils in shorter times.

Furth, Levine, and Waniek ${ }^{15}$ deduced an approximate expression for the rise in surface temperature of a conductor in a high field environment. They showed that the temperature rise was 


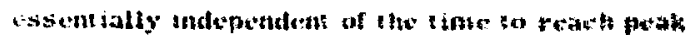

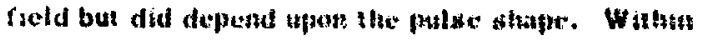

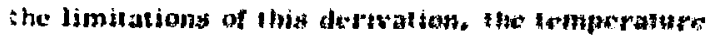

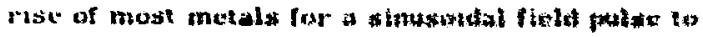
ilu rorst peak is given by:

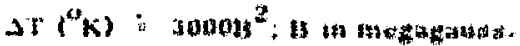

(3)

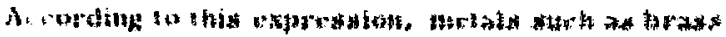

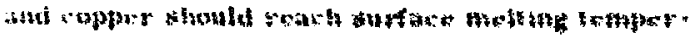

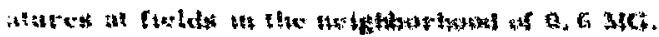

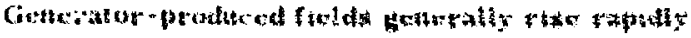

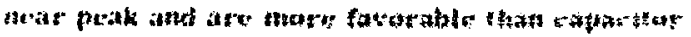

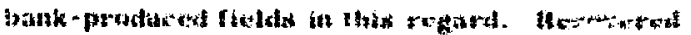

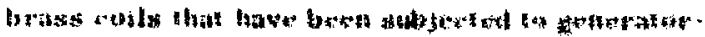

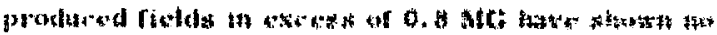

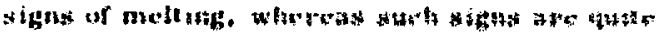

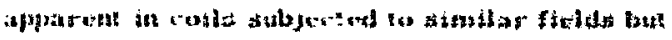

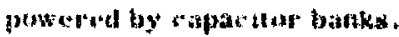

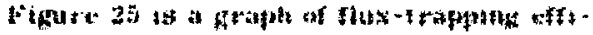

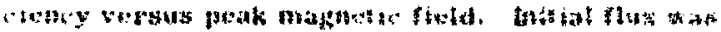

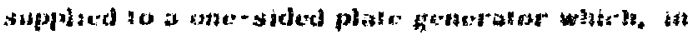

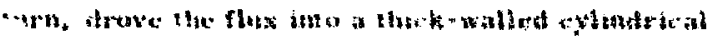

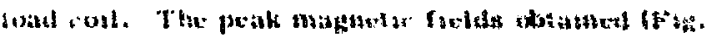

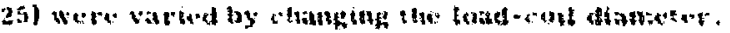

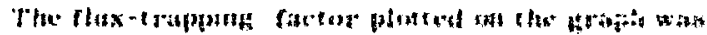

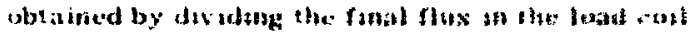

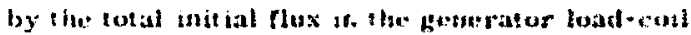
system. The peak field values ploted arz probably

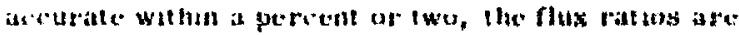
probibly somawhal less acrurate. For rields belovi bng KC. flux lusses agre less that $20 x$, but thory berome substintial above is MC. The magnetice pressure $\mathrm{B}^{2} / 8 \pi$ at $840 \mathrm{kC}$ is abois: $25 \mathrm{~kb}$, as noled beside the raghnet ic field ordinates of fig. 25.

The load-coil thuxes used in obtatning the flus-compression efficiencies of Fig. 25 were obtained by nultiplying the original roil rross * sectional areas by the peak midplanc ficld values. The coil eross sections probably werce enlarged by magnetic forces for those cases where peak fields were higher. Tius the loss in efficiency al higher ficlds is probably somewhat exaggerated.

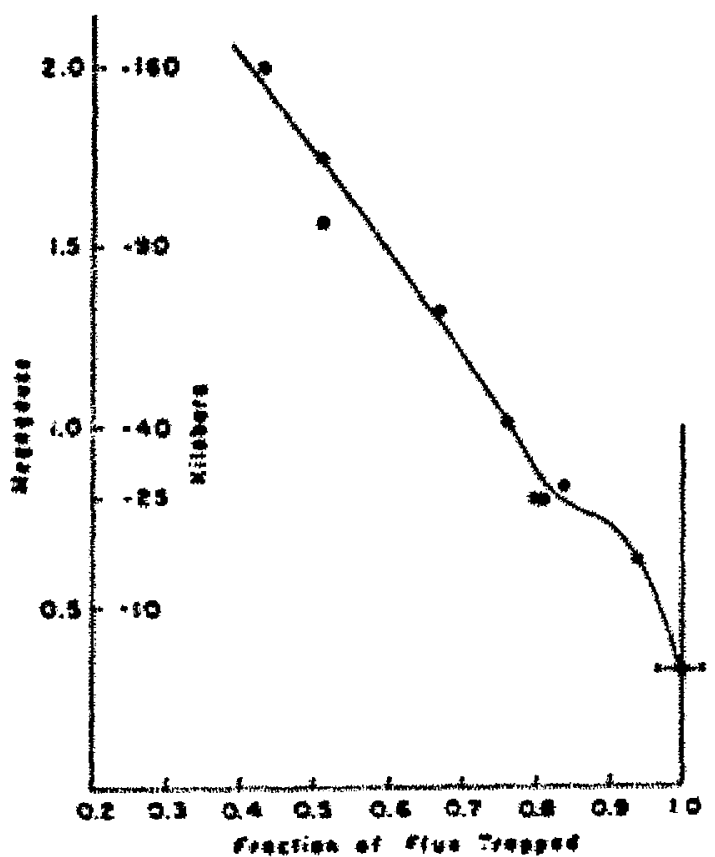

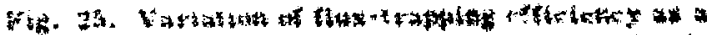
f(t)

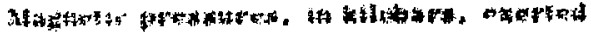

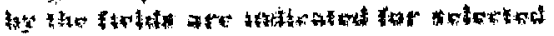

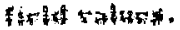

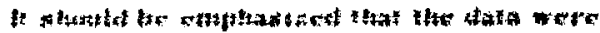
d45

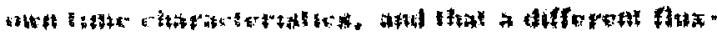

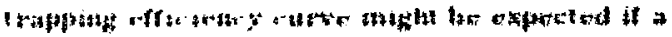

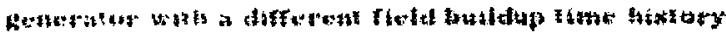

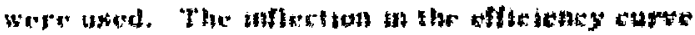

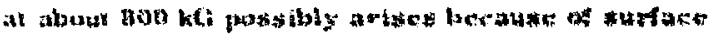

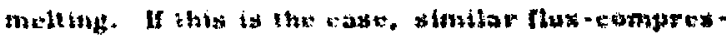

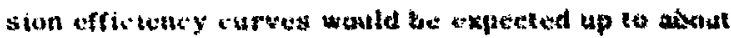
Ihis same ficld for ficld putses of differon length but similar stapims.

lligh ficld environmwns also arfect trankforaner toperalion adversely. Figures 23 athd 24 show, respet:ively, a transforaner coil as originally fabricated and as it appeared following a whot. The gross inward fadiad molion of the windtags arises rrom $\vec{i} \times \vec{B}$ magnetic rorces acting upon the wre. When th: magnetic fields surrounding the 


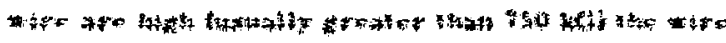

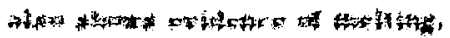

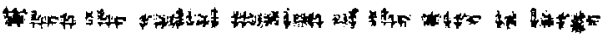

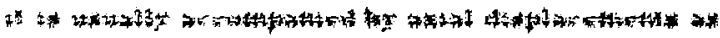

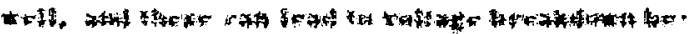

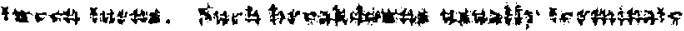

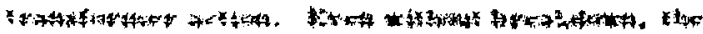

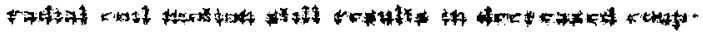

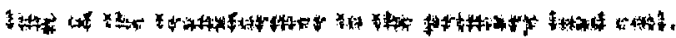

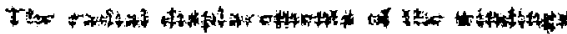

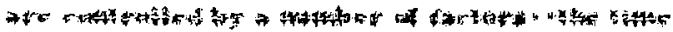

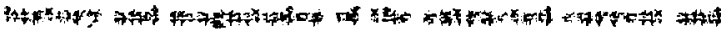

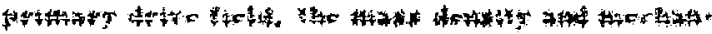

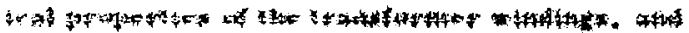

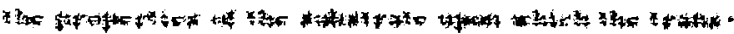

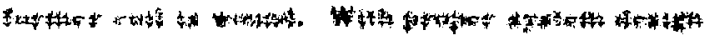

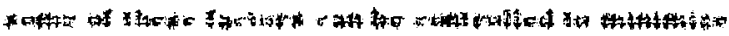

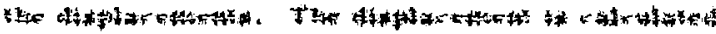

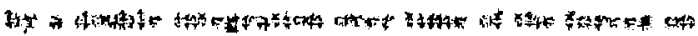

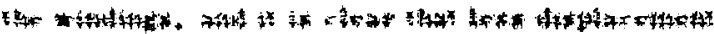

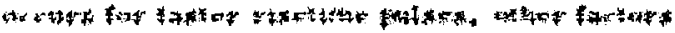

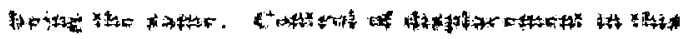

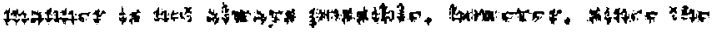

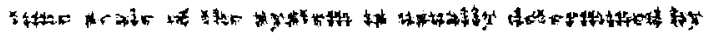

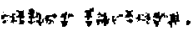

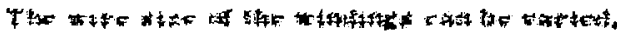

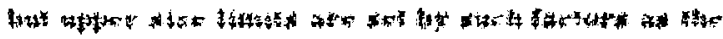

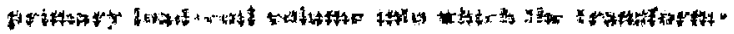

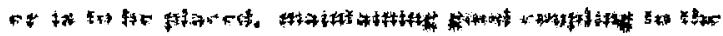

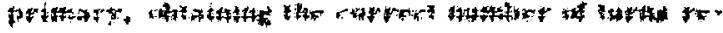

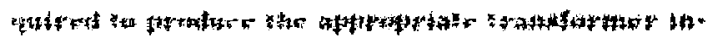

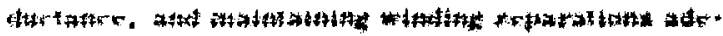

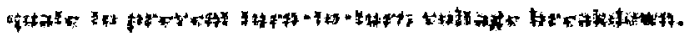

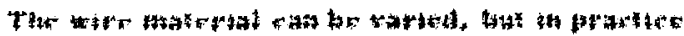

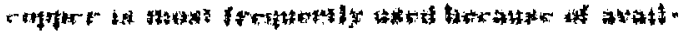

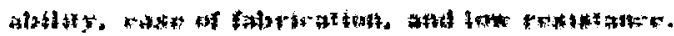

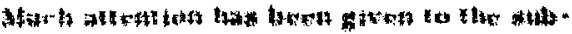

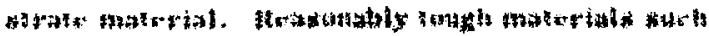

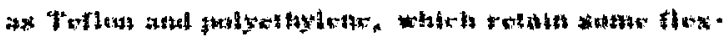

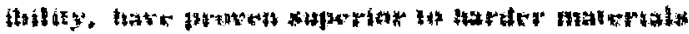

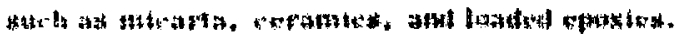

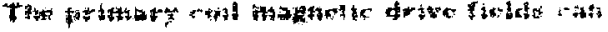

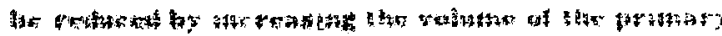

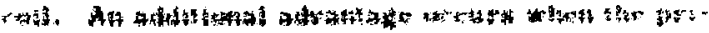
that

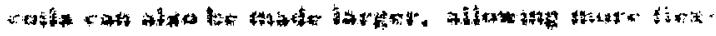

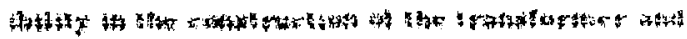

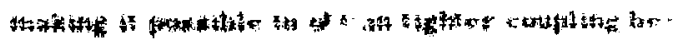
A

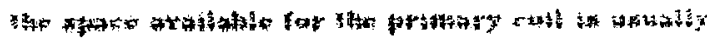

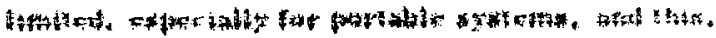

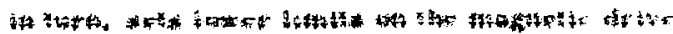

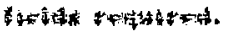

年蛙

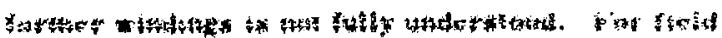

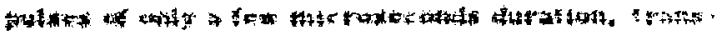

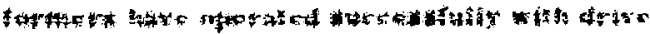

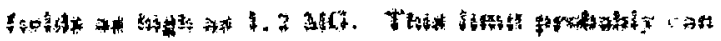

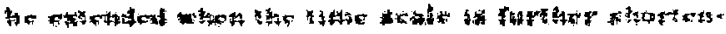

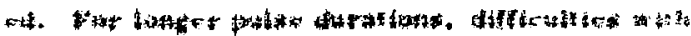

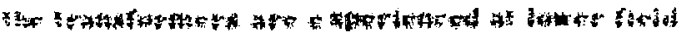

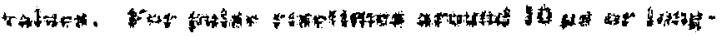

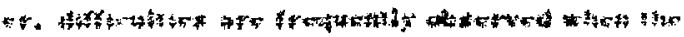

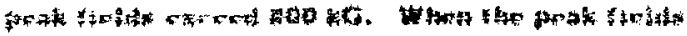

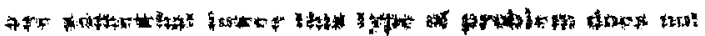

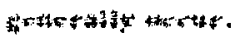

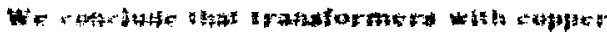
Wifl

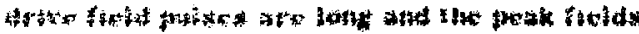

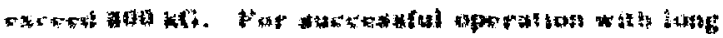

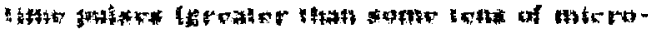

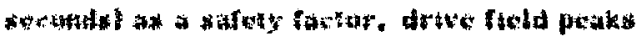

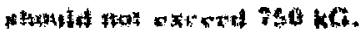

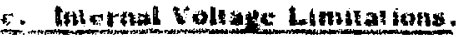

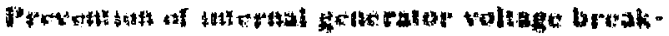

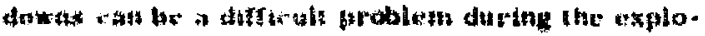

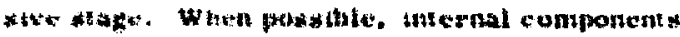

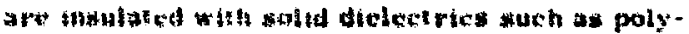

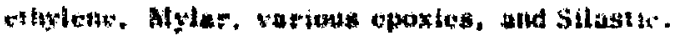

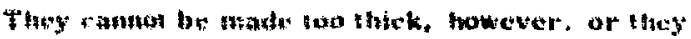

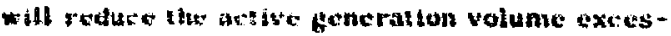
\$t+aty. 
Mctallic jets formed during this stage can form conducting paths which lead to breakdowns. Therse: jeets can arise at contact points of moving - ostutuctors and from defects in both metal and explosita componems.

The gas between armature and stator is

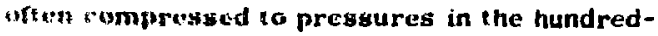
htlohne ratzu. and st be shock-heated to temperattros when is apprectably ionized. Air is Existe sitsceptible to tonitation from this cause than

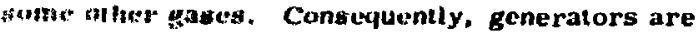
randataly pressurised with $\mathrm{SF}_{\mathrm{G}^{*}}$ various hydro"astowas of Freons, and in somo cases hydrogen or

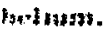

Spizal gonezotors aro more susceptible to was wall breakdown lhan other generators because for the mditional possibility of turti-to-turn breakduwl. Our focting, backed by considerable experi"tic. is that imtral voltages in spiral generators siluuld not far excect a hundred kilovolts. Con- withly. far latge enough generators the limit mblt be uxtended to $500 \mathrm{kV}$, but such a vollage woukl entatl ronsiderable risk.

W: huve mentioned that the voltage developed wat : Hellerator (across the moving armature) is Aven by the instantancous value of $\mathrm{iL}_{G}$ (see the discussion of lin. (13)). The presence of this volt itge make's it alnust impossible to supply large energites to large inductances in reasonable generalang rimes in a dreet or series feed situation such as that skot thed in Fig. 3. To get some feeling for the armature voltage developed, we consider a f.rterator of initual inductance $L_{o}$ delivering energy by dirent feed to a load $L_{1}$. Resistive losses and ither losises, such as flux pocketing, are accounted for lhrough usc of the figure of merit coefficient $\alpha$, at rording to liys. (33) and (34):

$\frac{I_{i}}{I_{0}}=\left(\frac{L_{0}+L_{1}}{L_{1}}\right)^{\alpha} ; \frac{E_{F}}{E_{0}}=\left(\frac{L_{0}+L_{1}}{L_{1}}\right)^{2 \alpha-1}$.
Here $E_{o}$ and $I_{0}$ designate the initial energy and current of the circuit, while $E_{F}$ and $I_{F}$ represent energy and current in the load at burnout. The figure of merit $\alpha$ is typically around 0.8 , although it may be higher if ideal multiplication ratios ( $L_{0}$ $+L_{1} / / L_{1}$ are relatively small, and smaller if these ratios are large.

As a specific example, suppose $10^{9} \mathrm{~J}$ are to be deposited in a load $L_{1}$ of $10 \mu \mathrm{H}$ and the initial energy in the system is $E_{0}=10^{7} \mathrm{~J}$. Then for $\alpha$ $=0.8$ the initial generator inductance $L_{o}$ wouid have to be $21000 \mu \mathrm{H}$. Some idea of the magnitude of such a generator can be obtained irom Eq. (15a). A generatur of $10-\mathrm{m}$ length, spiral radius of $5 \mathrm{~m}$, and armature radius of $3 \mathrm{~m}$ requires about 60 turns over the $10-\mathrm{m}$ length to have an inductance of $21000 \mu \mathrm{H}$. The spiral windings should gradually inc rease in width, reaching at least $14 \mathrm{~cm}$ at the output to handle the 14.1 MA required to energize the load. Even at this large current density, 1 $M A / c m$, the last turn alone, including its insulation spacing from the adjacent turn, would require about $30 \mathrm{~cm}$ of the total winding length of $10 \mathrm{~m}$. With a chemical explosive of relatively low detonation velocity, such as $7.5 \mathrm{~m} / \mathrm{ms}$, the burn time for a length of $10 \mathrm{~m}$ is $1.33 \mathrm{~ms}$. The armature expansion time required for a radial motion of $2 \mathrm{~m}$ could be as long as another couple of milliseconds or so, giving a reasonable total generator burnout time of about $4 \mathrm{~ms}$, maximum. As it turns out, even a burn time of this length results in internal generator voltages greater than $500000 \mathrm{~V}$, which in our opinion is still an unacceptable value. We can show that the internal generator voltage exceeds $500000 \mathrm{~V}$ by assuming that Eqs. (36) are valid during the entire generator operating time. The current is then given by:

$I=I_{0}\left(\frac{L_{0}+L_{1}}{L_{G}} \frac{1}{(t)+L_{1}}\right)^{\alpha}$. 
We seck the inductance tine behuvior of a generator whose maximum armature voltage is $\left|v_{0}\right|$. Since this voltage drives the entire system, the time required to anergize $L_{1}$ will be shurtest when the generator develops this limiting voltage during its entire generation time. Thus we have:

$\dot{L}_{G} I=I_{0} \frac{d L_{G}}{d t}\left(\frac{L_{0}+L_{1}}{L_{G}+L_{1}}\right)^{\alpha}=-v_{0}$

The solution to this equation becomes:

$L_{G}(t)+L_{1}=\left(L_{0}+L_{1}\right)\left[1-\frac{(1-\alpha) V_{0} T}{\left(L_{0}+L_{1}\right) I_{0}}\right]^{\frac{1}{T-\alpha}}$

The generator burnout time $T$ occurs when the right side of this equation reduces to $L_{1}$, or:

$T=\frac{\left(L_{0}+L_{1}\right) I_{0}}{(1-\alpha) V_{0}}\left[1-\left(\frac{L_{1}}{L_{0}+L_{1}}\right)^{1-\alpha}\right]$.

The initial generator inductance for $\alpha=0,8$ was $21000 \mu \mathrm{H}$ and the initial energy $10 \mathrm{MJ}$. The initial current $I_{0}$ is thus about $31000 \mathrm{~A}$. When these values are put into Eq. (40), it can be seen that the burnout time must exceed $6.5 \mathrm{~ms}$, if the armature voltage is not to exceed $500 \mathrm{kV}$.

A generato: with inductance characteristics as given by Eq. (39) would be difficult to construct. When more realistic generator forms are used (in Eq. (37)) the implications are worse. Still longer generation times are required to limit the internal voltages to $500 \mathrm{kV}$, a value already too high for a spiral generator. Some small gains can be made by increasing the initial energy in the generator circuit. In the example just considered, if the iritial energy $\mathrm{E}_{\mathrm{o}}$ were $20 \mathrm{MJ}$ instead of $10 \mathrm{MJ}$, the generator burn time could be reduced to about 5.2 ms while the armature voltage would still be maintained at $500 \mathrm{kV}$.
Uster thes" kinds of canditant we rancilede: lival $10^{\prime \prime}$ I eannot be generaled diroctly into a losed

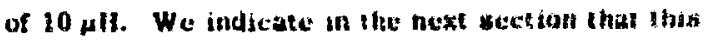
does appear feastble with use of tranglormer coupling.

E. Energizing throuth Transtormarz

From Eq. (40) it can ba seen that the ints: *

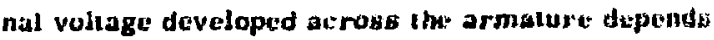
upon the initial generator flux divided by the fenerator time: Va(L $\left.L_{0}\right) / t^{2}$. This expression was derived for a specific example. In general, the situation is more tomplicated and tht: armature volt ages vary during generation. However, it is gianerally true that armature voltages are great ${ }^{\prime}$ witen the initial generator fluxes are larger and the generation times are short. The initial generator flux can be written as $L_{G} I_{0}=\left(2 E_{0} L_{0}\right)^{1 / 2}$, where $E_{0}$ $=1 / 2 \mathrm{~L}_{\mathrm{o}} \mathrm{I}_{\mathrm{o}}^{2}$, the initial generator energy. The armature voltage expression then becomes $v \propto\left(2 \mathrm{E}_{0} \mathrm{~L}_{\mathrm{o}}\right)^{1 / 2} / \mathrm{T}$. The problem of deliver.mg $10^{9} \mathrm{~J}$ to a load of $10 \mu \mathrm{H}$ by direct leed was considered in the previous section, where it was concluded that a spiral generator of $21000 \mu \mathrm{H}$ was required when the initial generator energy was $10 \mathrm{MJ}$. However, when the generation time was kept within reasonable limits, the resulting armature voltage was unmanageable. This is not surprising in light of the enormous initial flux associated with an inductance of $21000 \mu \mathrm{H}$ storing $10 \mathrm{MJ}$. We consider in this section the use of a generator to power a primary load coil directly. Energy is then delivered to the 10- $\mu \mathrm{H}$ load through transformer coupling to the primary load coil. It will be shown that, in principle, $10^{9} \mathrm{~J}$ can be delivered to the load when the initial generator inductance is only a few microhenrys and that, with an initial generator energy of $10 \mathrm{MJ}$, the armature voltages developed are quite manageable.

We consider the basic transformer coupled circuits sketclied in Fig. 21. The load to be energized is $L_{3}$, with an inductance of $10 \mu \mathrm{H}$. We take 


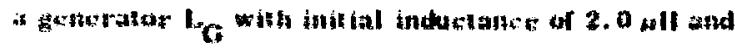

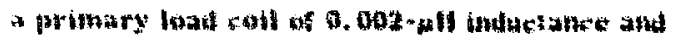

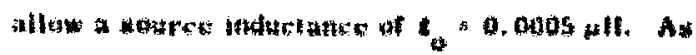

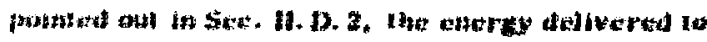

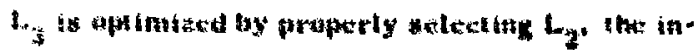

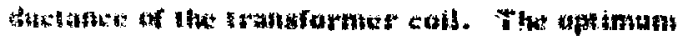

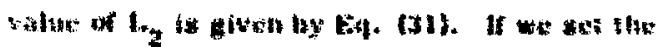

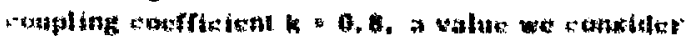

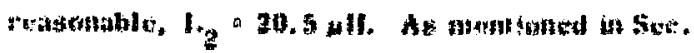

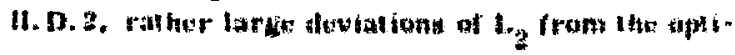

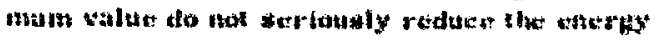

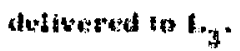

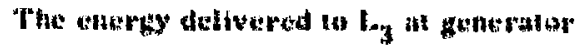

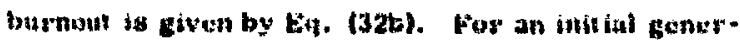

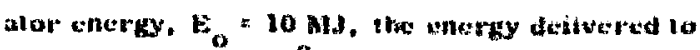

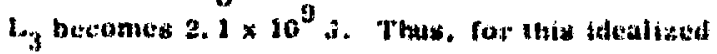

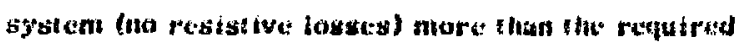
encrgy las boen elelivered to tik land. It remains to verify that the generator armature vollagi: is nustageablex.

Bquations (29ajandest are the solut ions for the two circuits sketehed in Pig. 21. By oliminating $I_{2}$ from inese equations the result ing expresston fon 1, becomes:

$I_{1}=I_{0} \frac{\left[L_{Q}+L_{1}\right]}{\left[L_{G}+L_{1}\right]}$

$(4 \mid a)$

where

$L_{1}{ }^{\prime}=L_{1} \cdot \frac{k^{2} L_{1} L_{2}}{L_{2}+L_{3}}$.

As in Sec. II. D. 3. C, we look for a generator with a time dependence such that the maximum allowable voltage $-v_{0}$ is generated across the armature throughout the entire generation time:

$i_{G} I=\frac{d L_{G}}{d t} I_{0}\left(\frac{L_{0}+L_{I}{ }^{\prime}}{L_{G}+L_{I}}\right)=-V_{0^{\circ}}$

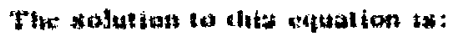

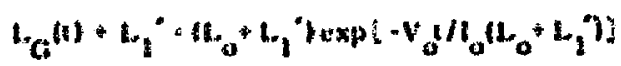

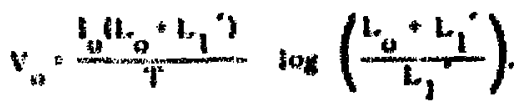

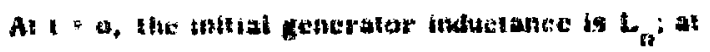

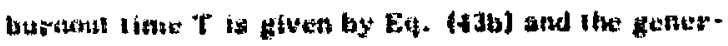

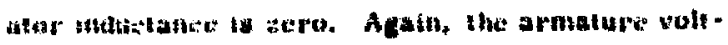

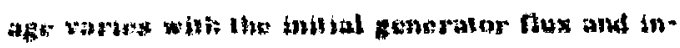

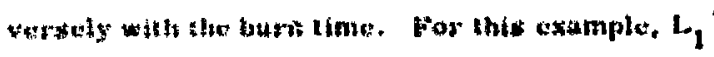

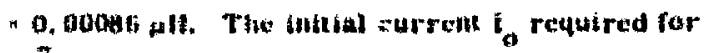
$10^{7} \mathrm{~J}$ in 2 wit is 3.16 MA. Wha a reasonable burm

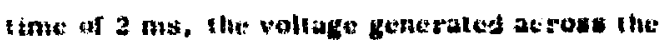

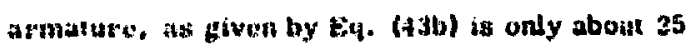
ky.

\section{ACKNOWI.HIXaIt:At'S}

We ar: priviledged to acknowledge the atsisiante of $\mathrm{A}$. M Eoirourt, D. J. Erickem. K. A. Fwing. R. M. Joppa, R, W. Livingston and, sh particular. that of $D$. B. Thomson. We are aiso byalcful for support from the Air Force Weapons Laboratory (Kirtland Al:B). the Defense Advanced Koseariti Projerts Agency, the U. S. Air Force loreign Techology Division (Wright - Patterson) and the U. S. A rmy Materiel Command, MicoM (Huntsuille).

\section{RLPFIRENCLSS}

l. H. Knoepfel, "Pulsed High Magnetic Fields," North-Folland (1970).

2. IF. Herlach, Prog, in Phys., XXXI, Part 1, p. 341 (1968).

3. C. M. Fowler, W. B. Garn, and R. S. Caird. "Production of Very High Magnetic Fields by Implosion," J. App. Phys. 31, 588-594 (1960). 
4. D. II. Cumbungs and M. 1. Mloricy in Pros.

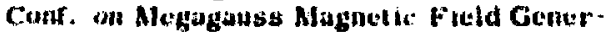
ation by Explosives and Halated Bxpryi-

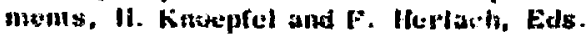
(kiurticm, Iatio), p. f5I.

3. A. D. Sahtharov, "Alagnetomplosive Gen"ratars," Sov. Plyss. Uspekthi (linglian Tratuliat tent 9. 29t-290 (1966).

6. J. U', Shatrevel al. "Explasive- Dritan Alapnet a " Fiald Compression Generators," 3. Apl. Phys. 39, 2102-2116 (19tit).

7. E. C. Crane and M. Cowal, "Pulsed Power fron lexplosive Generators," in Proi. symp. Engincering Prublems of Fusion Rescarch, Los Alamos Scientific Labora . lory report LA + 4250 (January 1979 ). Paper DI- 7.

B. F. F. Terman in Gadic biagincers Handbook (Mr:Craw-llill, 1943), p. 55 .

9. D. L. Thomson et at. "An Explosive" Generator-Powered 0-Pinch," in Proc. APS Topical Conf. on Pulsed High-Density Plasmas, Los Alamos Scientific Laboratory report LA-3770 (September 1967). Paper H-3.
10. K. A. Damerow el al. "Use of Explosive Conerulars to Power the 0-Pinch." in Prot. Symp. an Enginecring Froblems of fusian Hescarch, Los Alamos Scientific Laboratory repart LA-4250 (Sanuary 1970 ). Paper bl-8.

11. 11. S. Cuird el at. "Payload Exvelopment for a High Allitude Plasma Injeetion Exxper: merk (U)." LOS Alumos Scitentifis: Laborlary report LA-4302-MS (Orririal Use Only) (Pebruasy 1970).

12. E. I. Bixthenkov al al. "Experiments with an Explosive-Magnet le Gencrator in Lab. wratory Conditions, "Sov. Phys. Doklady (kinglish Translation) 13, 1256-1257 (1963).

33. C. M. Fowler at al., "LASL Group M-b Summary fleport. The Birdseed Program." Los Alamos Scientilic Laboratory report LA-5141-MS (January 1973).

14. "Technical Heport to ARPA," Los Alamos Scient ific Laboratory internal document (1972).

15. 11. P. Furth, M. A. Levine, and R. W. Wanick, "Production and Use of High Transient Magnetic Fields, 11,"Rev. Sci. Instrum. 28, 949-958 (1057). 